\title{
Emerging roles and the regulation of aerobic glycolysis in hepatocellular carcinoma
}

\author{
Jiao Feng ${ }^{1,2}$, Jingjing $\mathrm{Li}^{1,2}$, Liwei $\mathrm{Wu}^{2}$, Qiang $\mathrm{Yu}^{2}$, Jie Ji ${ }^{2}$, Jianye Wu${ }^{1^{*}}$, Weiqi Dai ${ }^{1,2,3,4,5^{*}}$ and Chuanyong Guo ${ }^{1,2^{*}}$ (D)
}

\begin{abstract}
Liver cancer has become the sixth most diagnosed cancer and the fourth leading cause of cancer death worldwide. Hepatocellular carcinoma (HCC) is responsible for up to $75-85 \%$ of primary liver cancers, and sorafenib is the first targeted drug for advanced HCC treatment. However, sorafenib resistance is common because of the resultant enhancement of aerobic glycolysis and other molecular mechanisms. Aerobic glycolysis was firstly found in HCC, acts as a hallmark of liver cancer and is responsible for the regulation of proliferation, immune evasion, invasion, metastasis, angiogenesis, and drug resistance in HCC. The three rate-limiting enzymes in the glycolytic pathway, including hexokinase 2 (HK2), phosphofructokinase 1 (PFK1), and pyruvate kinases type M2 (PKM2) play an important role in the regulation of aerobic glycolysis in HCC and can be regulated by many mechanisms, such as the AMPK, PI3K/Akt pathway, HIF-1a, c-Myc and noncoding RNAs. Because of the importance of aerobic glycolysis in the progression of HCC, targeting key factors in its pathway such as the inhibition of HK2, PFK or PKM2, represent potential new therapeutic approaches for the treatment of HCC.
\end{abstract}

Keywords: Hepatocellular carcinoma, Aerobic glycolysis, HK2, PFK1, PKM2, HIF-1a

\section{Background}

According to the latest global cancer statistics (2018), liver cancer has become the sixth most commonly diagnosed cancer and the fourth leading cause of cancer death worldwide in 2018 [1]. Because of the high infection rates of hepatitis $B$ virus (HBV) and hepatitis $C$ virus (HCV), the morbidity and mortality due to liver cancer is increasing in China [2]. Primary liver cancer is composed of hepatocellular carcinoma (HCC) (75-85\%) and intrahepatic cholangiocarcinoma (10-15\%), as well as other rare types [3]. The risk factors associated with primary $\mathrm{HCC}$ includes chronic $\mathrm{HBV} / \mathrm{HCV}$ infection, aflatoxin intake, alcohol abuse, smoking, obesity, and

\footnotetext{
*Correspondence: wjymail@163.com; dai_yue@163.com;

guochuanyong@hotmail.com

'Department of Gastroenterology, Putuo People's Hospital, Tongji University School of Medicine, number 1291, Jiangning road, Putuo, Shanghai 200060, China

Full list of author information is available at the end of the article
}

others [4]. Since the early-stage HCC is often asymptomatic, patients with $\mathrm{HCC}$ are usually diagnosed at intermediate or advanced stages, and miss the opportunity for curative treatment (hepatic resection or liver transplantation) [5].

For patients with advanced HCC, treatment options include local ablation, radiotherapy, chemotherapy and molecular targeted therapies [6]. Among them, sorafenib, a multi-target tyrosine kinase inhibitor, is the first line drug approved for the treatment of advanced HCC by the Food and Drug Administration (FDA) in 2005 [7, 8]. The famous Sorafenib Hepatocellular Carcinoma Assessment Randomized Protocol (SHARP) trial demonstrated that sorafenib improved patient overall survival for an extra 2.8 months [9]. However, the efficacy of sorafenib is limited owing to the development of drug resistance within 6 months [10]. The mechanisms responsible for sorafenib resistance are complex, but 
includes the activation of epidermal growth factor receptor (EGFR), c-Jun and the Akt pathway, as well as increases in cancer stem cells, and enhancement of epithelial-mesenchymal transition (EMT) [11].

There are six hallmarks of cancer, including sustained proliferative signaling, evasion of growth suppression, resistance to cell death, replicative immortality, inducing angiogenesis, and activation of invasion and metastasis [12], all of which contribute to the malignant biological properties of cancer. Recently, new theories are emerging that energy metabolism reprogramming may be another hallmark of cancer [13]. In the 1920s, Otto Warburg firstly showed that unlike normal cells that catabolize glucose by oxidative phosphorylation in the mitochondria, tumor cells tend to convert glucose into lactate even in conditions of sufficient oxygen [14]. This phenomenon was termed as aerobic glycolysis or the Warburg effect, and is characterized by enhanced glucose uptake and lactate production. Although the adenosine triphosphate (ATP) production efficiency is low during aerobic glycolysis, it still takes up to $50-70 \%$ of the ATP supply in different tumors [15]. Furthermore, the metabolic intermediates generated during aerobic glycolysis can be used for the biosynthesis of biomacromolecules used by the tumor to meet the demands for rapid growth [16]. The production of lactate also provides an acidic environment to aid the invasion and metastasis of cancer [17]. Moreover, some researchers have found that increases in aerobic glycolysis are also involved in sorafenib resistance [18].

Aerobic glycolysis plays an important role in the proliferation, growth, invasion and treatment of cancer. A better understanding of aerobic glycolysis in HCC will help to reveal the pathogenesis and potential treatment paths for HCC, as well as the mechanism of sorafenib resistance [19]. Therefore, this review aimed to review the characteristics and regulatory mechanisms of aerobic glycolysis in HCC, and to identify potential new therapeutic targets for its treatment.

\section{Characteristics of aerobic glycolysis in HCC}

\section{Enhancement of aerobic glycolysis in HCC}

The Warburg effect was firstly reported in rat liver carcinoma in the 1920s. Warburg and his co-workers found that rat liver carcinoma did not consume more oxygen $\left(\mathrm{O}_{2}\right)$ than normal liver tissue; but instead, even in the presence of sufficient $\mathrm{O}_{2}$, liver carcinoma tissue also converted glucose and pyruvate into lactate, rather than transferred pyruvate into the mitochondria for use in the citric acid cycle. Moreover, Cori C. F. and Cori G. T. further reported that the blood drawn from a Rous sarcoma tumor containing veins showed significantly less glucose and more lactate than normal tissues [14]. After these initial findings, this enhancement of aerobic glycolysis has been found in many other cancer types, including breast cancer [20], renal cell carcinoma [21], pancreatic cancer [22], lung cancer [23], gastric cancer [24], and prostate cancer [25]. The existence of aerobic glycolysis in HCC has also been proved by Li S [26], Beyoğlu D [27] and Bustamante E [28], which found that the aerobic glycolysis was enhanced in $\mathrm{HCC}$ as well as hepatoma.

Warburg originally hypothesized that the mitochondrial respiration (also known as oxidative phosphorylation, OXPHOS) must be damaged in cancer cells because they used high levels of $\mathrm{O} 2$, and found that they were unable to suppress lactate production in cancer cells. However, Chance and Weinhouse in 1950s firstly found that there were no mitochondrial defects in cancers, opposing to Warburg's conception [14]. Currently, many researches still believe that the mitochondria are not injured in cancers and OXPHOS remains functional for the supply of $\mathrm{O}_{2}$ [29]. However, there have also been studies reporting mutations in mitochondrial DNA (mtDNA), specifically those genes coding for proteins involved in OXPHOS, such as point mutation (52\% of HCC patients), gene deletions or insertions, and copy number changes [30,31], and there exists a dysfunction in coenzyme Q10 [32] and other components of the mitochondrial electron transport chain [33]. Drugs targeting mitochondria, such as oligomycin, combined with antiglycolysis drugs, such as 2-deoxyglucose (2-DG), showed a synergic effect in triggering cancer cells death [34].

Although aerobic glycolysis has been observed in many cancers, most cancer cells do not utilize aerobic glycolysis alone. Instead, they consume ATP from both the mitochondria OXPHOS and the aerobic glycolysis. In most normal cells, the ATP produced from mitochondria OXPHOS and glycolysis is approximately 90 and $10 \%$, respectively. Whereas cancer cells rely on aerobic glycolysis to provide as much as $60 \%$ of the ATP consumption [35]. It's well known that the mitochondrial OXPHOS can produce 36 molecules of ATP, while the use of glycolysis to synthesis lactate can just produce only 2 molecules of ATP. Although the aerobic glycolysis seems to be energetically inefficient in the production of ATP, this is compensated for by the fact that the aerobic glycolysis process is more rapid and it also generates further downstream biomacromolecules required for cell proliferation [36]. Rapid glucose fermentation by glycolysis also causes cancer cells to take up more glucose than normal cells [37]. These findings suggest that the use of aerobic glycolysis in HCC provides advantages during cancer progression.

\section{Key enzymes in aerobic glycolysis in HCC}

There are three rate-limiting enzymes in aerobic glycolysis, including hexokinase (HK), phosphofructokinase 
(PFK), and pyruvate kinases (PKs) (Fig. 1). The expression changes of these enzymes can largely influence the progression of HCC.

\section{Hexokinase 2 (HK2)}

Hexokinase (HK) is the first rate-limiting enzyme in aerobic glycolysis and can catalyze the conversion of glucose to glucose-6-phosphate (G-6-P) [38]. The enzymes have four isoforms (HK1, HK2, HK3 and HK4), but most normal tissues express only HK1. However, HK2 is highly expressed in HCC tissues and it is directly linked to pathological stage and patient prognosis [39].

HK2 is more efficient at promoting aerobic glycolysis than the other isoforms [40], and the mechanisms by which HK2 promotes glycolysis has been investigated by many researchers. Firstly, HK2 interacts and binds to the voltage-dependent anion-selective channel protein 1 (VDAC1) in the mitochondrial outer membrane, then facilitates the activation of ATP synthesis-related enzymes to enhance the production of ATP and the inhibition of apoptosis (Fig. 1) [41]. Secondly, when HK2 is bound to VDAC1, it is protected from the inhibitory effects of its downstream products, such as G-6-P, thereby enhancing the glycolysis process and the rate of ATP production [15]. The expression of HK2 is controlled by several signaling pathways and transcription factors, including the PI3K/Akt/HIF- $1 \alpha$ axis, $\beta$-catenin/c-Myc signaling pathway, STAT3, and miR-199a [42-45].
Recently, a novel isoform has been found termed hexokinase domain containing 1 (HKDC1). Normally, HKDC1 is upregulated in pregnant women at 24-28 weeks of gestation and regulates the whole-body glucose homeostasis during pregnancy through its role in glucose use [46]. However, Zhang et al. reported in 2016 that HKDC1 is also overexpressed in HCC and is associated with a lower overall survival, possibly through the upregulation of the $\mathrm{Wnt} / \beta$-catenin pathway, causing increased HCC cell proliferation and migration [47].

It has been reported that genetic liver-specific knockout of HK2 decreases the proliferation and the formation of HCC induced by diethylnitrosamine. HK2 depletion inhibits glycolysis flux and induced OXPHOS, enhancing the sensitivity of HCC to drugs, such as metformin. Moreover, HK2 silencing can synergistically enhance the sensitivity of HCC to sorafenib, thereby inhibiting tumor growth in mice [39]. Based on the key role of HKs in HCC, HK2 is considered to be a highly promising metabolic target for the development of new treatments for HCC.

\section{Phosphofructokinase-1 (PFK1)}

Phosphofructokinase-1 (PFK1) is the second ratelimiting enzymes involved in glycolysis, and can catalyze fructose 6-phosphate(F-6-P) to fructose 1,6-bisphosphate (F-1,6-BP) using ATP [48]. There are three isoforms of PFK1 in mammals, which are PFK-M (found in muscle),

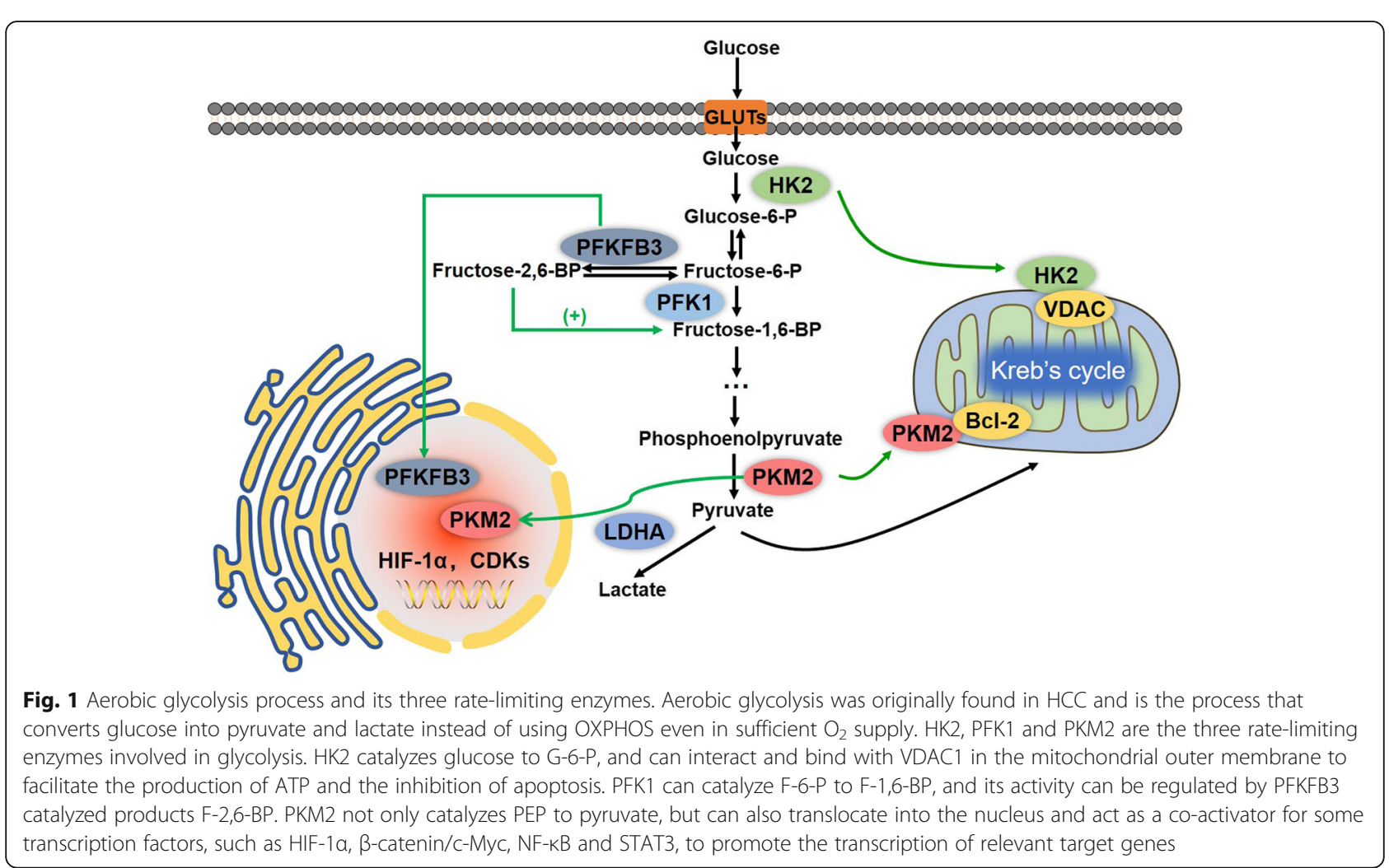


PFK-P (found in plasma) and PFK-L (found in liver), and the proportion of these isoforms may vary in different tissues depending on their specific energy metabolism requirements [49]. In liver, it has been reported that expression levels of PFK-L, PFK-M, and PFK-P subunits are expressed in this descending order in humans and in rats [48].

PFK1 is primarily synthesized as an unstable and inactive monomer, which can then rapidly form dimers, which maintains the minimal catalytic activity for F-6-P [50]. However, the fully activated PFK1 is present as a tetramer, and the formation and stabilization of PFK1 tetramers largely influences the glycolytic flux rate largely [51]. However, the downstream products of PFK1 enzymes, including ATP, phosphoenolpyruvate (PEP), citric acid and lactate, can induce the dissociation of PFK1 tetramers to dimers, leading to the inhibition of PFK enzymatic activity and providing a negative feedback to the glycolytic process [52]. However, increased PFK-1 activity has been found to promote glycolysis and proliferation in cancer cells [53]. For example, fructose 2,6 - bisphosphate (F-2,6-BP), which is also the product of F6P catalyzed by PFKFB3 (Fig. 1), is considered to be the most potent allosteric activator of PFK1, and can increase PFK1 activity even in the presence of ATP [51].

As mentioned above, the enzymes 6-phosphofructo-2kinase/fructose-2,6-bisphosphatase-3 (PFK2/PFKFB-3) play a significant role in the regulation of glycolysis in HCC, as well as in tumor growth and metastasis [52, 54]. PFKFB3 can translocate into the nucleus to regulate the activity of cyclin-dependent kinase (CDKs), resulting in the arrest of the cell cycle and the inhibition of cell death (Fig. 1) [55]. Moreover, overexpression of PFKFB3 can increase the expression of VEGF-A, thereby promoting angiogenesis and facilitating metastasis in breast cancer [56]. By inhibiting PFKPB3, aspirin in combination with sorafenib, overcomes sorafenib resistance by inducing apoptosis in HCC [54]. The expression of PFKFB3 can also be regulated by hypoxia inducible factor- $1 \alpha$ (HIF-1 $\alpha$ ) mediated transcription, AKT, and PTEN [57].

In many cancer types, high levels of PFKFB3 are correlated with poor prognosis with lymph node metastasis or poor survival $[58,59]$. Therefore, targeting PFKFB3 can also be a new therapeutic approach for the treatment of HCC.

\section{Pyruvate kinases, type M2 (PKM2)}

The last rate-limiting enzymes in glycolysis process are pyruvate kinases (PKs), which catalyze PEP to produce ATP and pyruvate. There are also four isoforms of PKs, including liver-type PK (PKL), red blood cell PK (PKR), and PK muscle isozymes M1 and M2 (PKM1 and PKM2, respectively) [60]. Unlike other forms of PKs,
PKM2 is highly up-regulated in cancer cells, and is associated with a poor prognosis [35].

The activity of PKM2 is mainly controlled by its oligomerization states (Fig. 2). There are two forms of PKM2, one is a tetramer, with higher catalytic activity, and is located in the cytoplasm and can transform PEP to pyruvate rapidly, the glycolytic flux and the production of more ATP [61]. However, the other isoform is a monomer or dimer, with lower catalytic activity, and can translocate into the nucleus to act as a co-activator of several transcription factors, such as HIF- $1 \alpha, \beta$-catenin/ $c-M y c, N F-k B$ and STAT3 $[60,62]$. Once in the nucleus, PKM2 can promote the transcription of target genes, such as HIF- $1 \alpha$ targeted expression of GLUTs, PKM2, LDH-A, and VEGF-A, leading to the promotion of growth, positive feedback regulated-glycolysis and angiogenesis in cancer cells [63].

The activity of PKM2 can also be regulated by numerous allosteric effectors and post-translational modifications. For example, the upstream metabolic intermediates F-1,6-BP can act as an allosteric activator to increase the activity of PKM2; while the downstream products such as ATP and L-cysteine can inhibit PKM2 activity [64-66]. PKM2 can also be post-translationally modified. The phosphorylation at Tyr105, Tyr 328, Thr328 or Pro403/408 sites, or the succinylation at K498 site, or acetylation at K433 site of PKM2 has been demonstrated to inhibit the tetramer formation and activity of PKM2, but promotes its nuclear translocation $[64,65$, $67,68]$. Moreover, PKM2 can also interact and bind with some oncogenic proteins, including pp60v-src, to increase dimer formation [69]. Heterogeneous ribonucleoprotein (hnRNP) also influences the alternative splicing of PKM genes, giving rise to differences in the PKM1/PKM2 ratio [70]. Some signaling pathways, such as HIF- $1 \alpha$, PI3K/mTOR and PPAR- $\gamma$, also upregulate the expression of PKM2 to promote the growth of cancer cells [71].

Since its discovery in HCC, and the over-expression of PKM2 has been found in many other cancer types, including cervical cancer, lung cancer, breast cancer, colorectal cancer, and prostate cancer, especially the lower activity dimer form of PKM2 [72]. Recently, it has been reported that the expression levels of PKM2 are associated with the clinicopathological features of HCC, such as the size, the number and the clinical stages of tumors. HCC patients with higher levels of PKM2 expression exhibit a higher cumulative recurrence rate than those with lower PKM2 levels [73]. By switching from PKL to PKM2, HCC cells can elevate glucose uptake levels and increase the oxidative stress [74]. There are also some specific inhibitors, such as compound $3 \mathrm{k}$ and shikonin, which have the ability to inhibit the formation of PKM2 tetramers, thereby inhibiting the growth of $\mathrm{HCC}$, and 


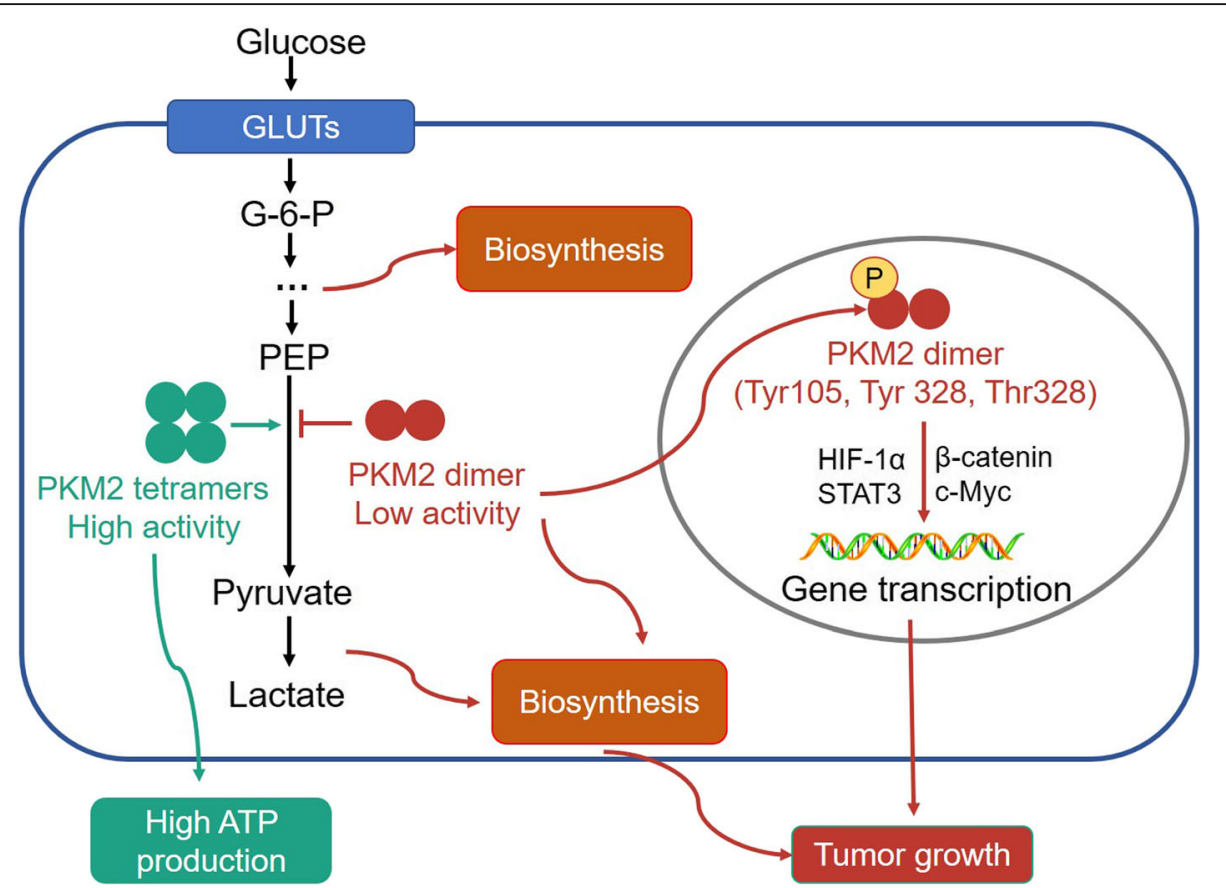

Fig. 2 The activity of PKM2 is dependent upon its oligomerization states. The PKM2 tetramer exhibits high levels of pyruvate kinase activity and can accelerate the transformation of PEP to pyruvate, thereby increasing the glycolytic flux and ATP production rates. Whereas PKM2 in dimeric form exhibits lower levels of pyruvate kinase activity, and can be phosphorylated at Tyr105, Tyr 328, Thr328 or Pro403/408 sites and then translocate into nucleus to act as a co-activator for some transcription factors, such as HIF-1a, $\beta$-catenin/c-Myc, NF-KB and STAT3, leading to tumor progression

making PKM2 another therapeutic target for the treatment of HCC $[75,76]$.

\section{Role of enhanced aerobic glycolysis in HCC} Proliferation, growth and immune evasion in HCC

As a new hallmark of HCC, aerobic glycolysis is believed to promote the proliferation, growth, and induce immune evasion in HCC through the following evidence: (1) there is rapid ATP production during aerobic glycolysis, enabling the tumor to adapt to its microenvironment which is short of energy resources [41]. (2) The enhanced aerobic metabolism is accompanied by activated glycolytic flux, with increased amounts of metabolic intermediates production, such as dihydroxyacetone phosphate (DHAP, which can be used for the synthesis of triglycerides and phospholipids), 3phosphoglycerate (3-PG, which can be used for the synthesis of amino acids). These can then enter other metabolic pathways for the synthesis of nucleotides, lipids, and proteins, enabling cancer cell proliferation [77]. Cancer cells also elevated the aerobic glycolysis to promote glutaminolysis to satisfy the precursor needs required for nucleic acids biosynthesis [78]. (3) The production of lactate, as well as the hydrogen ions $\left(\mathrm{H}^{+}\right)$ produced during these processes, cause the acidification of the extracellular environment, which inhibits the function of immunosuppressive cells, including M2 type macrophages and lymphocytes, further facilitating the survival of cancer cells [36].

Many studies have found that the pro-survival effect of aerobic glycolysis in HCC is caused by the inhibition of enzymes involved in glycolysis. For example, in xenograft models, HK2 knockdown by shRNA can reduce the growth rates of Hep3B liver tumors by approximately $50 \%$ [26]. Furthermore, inhibition of PFKFB3 using specific inhibitors or shRNA, suppresses the growth of $\mathrm{HCC}$ both in vivo and in vitro [54]. Knockdown of PKM2 by siRNA also inhibits the proliferation of HCC cell lines [79], and the downregulation of LDH-A can also induce apoptosis and growth arrest in a HCC xenograft mouse model [80].

\section{Invasion and metastasis in HCC}

The malignant and aggressive nature of cancers can be reflected by the extent of metastasis and invasion. Many studies have found that the metastasis and invasion of HCC are correlated with the enhanced aerobic glycolysis in HCC. For example, Li et al. found that in different $\mathrm{HCC}$ cell lines, those that exhibited the greatest invasion capability, including MHCC-97H, HCC-LM3, showed a high level of aerobic glycolysis when compared to less invasive cell lines such as HepG2 [54, 75, 81]. These 
phenomenon were also common in breast cancer, prostate cancer, cervical and head and neck cancers [82].

Because of the hypoxic nature of tumor tissues, cancer cells tend to metastasize to additional sites to enhance energy and blood supplies, thereby enabling its survival. The glycolytic phenotype aids this metastasis and invasion in $\mathrm{HCC}$ mainly through lactate and $\mathrm{H}^{+}$mediated acidification of the extracellular environment, which includes the following aspects: (1) the low $\mathrm{pH}$ in extracellular environment causes destruction of the normal tissue through caspase-mediated or p53-dependent apoptosis [83]. (2) Acidification of the extracellular matrix (ECM) promotes the secretion of proteolytic enzymes such as cathepsin B or metalloproteinases, so as to help the degradation of ECM and facilitate metastasis [82]. (3) The immunosuppression caused by low $\mathrm{pH}$ levels also enables metastatic cancer cells to escape the surveillance of immune system, leading to the sustained metastasis [84]. As a result, aerobic glycolysis is responsible for the extracellular structure and immunosuppression, making it easy for cancer cells to metastasize and invade.

\section{Angiogenesis in HCC}

Angiogenesis, also known as neovascularization, is a pathologically abnormal vessels formation in $\mathrm{HCC}$, which supply the necessary requirement for rapid tumor growth and initiation of metastasis [85]. Angiogenesis in HCC is also driven by hypoxia. As mentioned above, HCC is a solid tumor, and its structure consists of a tumor surrounding stroma, basal membrane, tumor tissues, and central necrosis [82]. Therefore, there is hypoxia in tumor tissues due to its specific tumor tissues structures. However, though the angiogenic factors, such as vascular endothelial growth factor (VEGF) and the angiopoietin families (Angs), can be released by hypoxia in cancer cells, the new vessels remain physically separated from cancer cells due to the existence of basement membranes. Therefore, although HCC is largely dependent on angiogenesis for its energy supply during invasion and metastasis, the metastasis and invasion processes also favor the angiogenesis by destroying the ECM structures [86].

In fact, it's believed that the 'glycolytic switch' occurs before the angiogenesis [82]. Aerobic glycolysis also causes angiogenesis process in HCC through many pathways. For example, the acidification of the extracellular environments by lactate and $\mathrm{H}^{+}$can promote the secretion of VEGF and interleukin 8, which are both angiogenic factors and can induce angiogenesis [87, 88]. Moreover, the production of pyruvate by glycolysis can also induce the expression of HIF- $1 \alpha$ and accelerate the angiogenesis process by mediating the transcription of VEGF and plasminogen activator inhibitor-1 (PAI-1) in
HepG2 cells. HIF-1 $\alpha$ can also promote the expression of the glycolytic enzymes, such as PKM2, HK2 and LDHA to promote glycolysis in tumors, which forms a positive feedback loop for tumor progression [88].

\section{Drug resistance in $\mathrm{HCC}$}

The enhancement of aerobic glycolysis can also contribute to drug resistance in HCC. It has been reported that high glycolysis levels were significantly associated with poor prognosis in cancer chemotherapy in combination with bevacizumab [89]. Furthermore, Li et al. and Feng et al. found that the aerobic glycolysis was enhanced in different HCC cell lines, and was associated with sorafenib resistance. By downregulating PFKFB3 or PKM2, the sorafenib resistance seen in HCC can also be improved $[54,75,90]$. Moreover, combined treatment with sorafenib and 2-DG, which is a HK2 inhibitor, can synergistically suppress the proliferation of sorafenib resistant HCC cells by inhibiting ATP production [91].

The mechanisms by which aerobic glycolysis influences drug sensitivity in HCC can be concluded as: (1) HK2 can enter the mitochondria and interact with VDAC, inhibiting the release of cytochrome c and subsequent apoptosis, leading to the inhibition of cell death [92]. (2) Some signaling pathways, such as the PI3K/ Akt/mTOR pathway, can activate HK2 and PKM2 in cancer cells and promote their survival and drug resistance [93]. (3) The pyruvate dehydrogenase (PDH), which catalyze pyruvate into acetyl coenzyme A, can be inactivated by PDH kinase and then promote the synthesis of lactate. The decreased level of PDH has been reported to be responsible for sorafenib-acquired resistance in HCC, and this effect can be reversed by using a PDH kinase inhibitor [94]. (4) PKM1 is also reported to promote aerobic glycolysis through autophagy and cause cancer chemoresistance [95]. (5) HIF-1 $\alpha$ and c-Myc also participate in chemoresistance in HCC, as there is elevated expression of HIF- $1 \alpha$ and c-Myc in HCC tissues, and these have been found to target the multi-drug resistance (MDR) gene MDR1 [96]. (6) Besides, the immunosuppression caused by acidification of the extracellular environment also contributes to drug resistance [97].

\section{Regulatory mechanisms of aerobic glycolysis in HCC \\ AMP-activated protein kinase (AMPK)}

The AMPK is a highly conserved Ser/Thr kinase consisting of catalytic $\alpha$, regulatory $\beta$, and $\gamma$ subunits, and acts as a key energy status sensor and energy homeostasis regulator, including glucose, protein and lipid metabolism and autophagy [52]. During energetic stress, AMPK inhibits the ATP consuming processes, such as lipid and protein biosynthesis and cell proliferation, while promoting the ATP conserving process, such as autophagy and 
glycolysis [98]. AMPK is usually activated by the serine/ threonine kinase liver-kinase-B1 (LKB1) with Thr172 phosphorylation during energy stress [99]. It has been found that the phosphorylation of AMPK by noncanonical upstream kinases can also affect AMPK activity. For example, the phosphorylation of Ser485 in AMPK $\alpha 1$ and Ser491 in AMPK $\alpha 2$ by PKA, and phosphorylation of Ser491 in AMPK $\alpha 2$ by p70S6 kinase (S6K) can suppress AMPK activity [100, 101].

AMPK plays important roles in the growth, proliferation, autophagy, angiogenesis, metastasis and invasion, and stress response in HCC. For example, Fang et al. reported that the activation of AMPK/mTOR pathway can suppress the HCC malignant phenotype by inhibiting glycolysis [102]; whereas loss of AMPK activation was associated a poor prognosis in HCC patients [103]. Faubert $\mathrm{B}$ et al. also reported that genetic ablation of AMPK $\alpha 1$ can accelerate Myc-induced lymphomagenesis and elevate the aerobic glycolysis level, which was through the stabilization of HIF-1 $\alpha$ [104, 105]. On the contrary, emerging evidence suggested that AMPK can protect cancer cells from metabolic stress to promote tumor progression [106]. Furthermore, it has been found that the activation of AMPK/mTOR pathway in HCC cells was associated with bile acid induced invasion and migration of HCC [107].

AMPK is a crucial link between metabolism and signaling pathways. The mechanisms by which the activation of AMPK during energetic stress can regulate glycolysis can be concluded as follows. Firstly, AMPK can promote glucose uptake by enhancing the expression of GLUT4 and GLUT1 in cell membrane through the PI3K pathway (Fig. 3) [52, 108, 109]. Secondly, under hypoxia status, AMPK can mediate the activation of PFK2 (PFKFB3) to enhance glycolysis in myocardia. By AMPKdependent phosphorylation of PFKFB3, the metabolic pattern in tumor cells is switched from oxidative respiration to glycolysis [110]. Thirdly, AMPK has been reported to increase the expression levels of PFKFB3 [108].

AMPK also plays a vital role in autophagy to affect the malignance of HCC. Conventionally, autophagy is activated by mitochondrial depolarization, nutrient starvation, toxic proteins aggregation and infection, leading to deregulation of biomacromolecules for energy supply [111]. However, autophagy is constitutively activated in HCC, and participates in tumorigenesis, metastasis, glycolysis, targeted therapy and drug resistance of HCC through AMPK dependent or independent pathways [112]. Recently, more and more studies have shown that autophagy plays a dual role in HCC. In tumor cells, autophagy protects the survival of tumor cells via the following mechanisms: (1) promotion of metabolite turnover and energy production; (2) inhibition of apoptosis and reactive oxygen species production; and (3) inducing drug resistance [113]. Except for the tumor promotion effect of autophagy, it has also been found that autophagy also has a tumor suppressive effect during the progress of liver cancer. These can be reflected by $\mathrm{Qu}$ et al. that knockout of autophagy gene BECLIN1 could induce HCC tumorigenesis in mice [114].

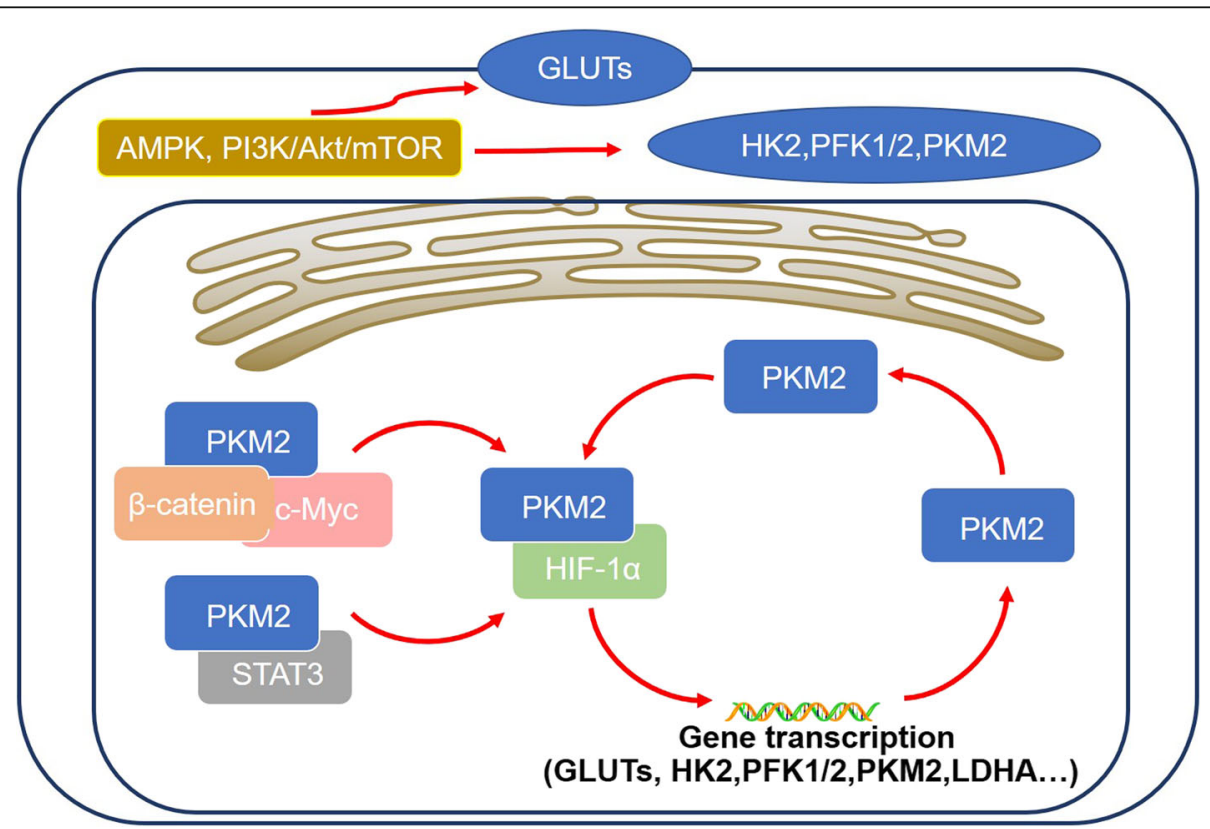

Fig. 3 Regulatory mechanisms involved in aerobic glycolysis in HCC. Aerobic glycolysis can be regulated by various transcriptional factors, such as HIF-1a and c-Myc, and many signaling pathways, such as AMPK and PI3K/Akt, as well as noncoding RNAs. The regulatory mechanisms include the regulation of enzymes activity and the relative gene expression levels, and both mechanisms are tightly intertwined 
Typically, after the activation of AMPK, mTOR is further inhibited, and then results in the inhibition of autophagy process. Kim et al. reported that under glucose starvation, AMPK promoted autophagy by directly activating ULK1 (an ATG1 homologue) through phosphorylation of Ser 317 and Ser 777. And under nutrient sufficiency, high mTOR activity prevents ULK1 activation by phosphorylating ULK1 Ser 757 and disrupting the interaction between ULK1 and AMPK [115]. Besides, phosphorylation of AMPK suppresses mTORC1 mediated inactivation of Raptor or activation of TSC2 [111]. On the other hand, autophagy can be activated through various AMPK independent pathway, such as the PI3K/AKT/mTOR pathway, MAPK/ERK signaling pathway, transcription factors including $\mathrm{c}-\mathrm{Myc}$ and p53 [116, 117].

Collectively, these findings provide a further prospect that AMPK is a promising target in the treatment for HCC.

\section{PI3K/Akt pathway}

The phosphoinositide 3-kinases (PI3Ks) signaling pathway play important roles in both growth control and glucose metabolism of cancer cells. The PI3Ks include three major classes of lipid kinases, termed class I (including Ia and Ib), class II, class III, and a distantly related Class IV [118]. Akt (also known as protein kinase B) is a serine/threonine protein kinase directly activated by PI3K [119]. The PI3K/Akt pathway regulates a broad range of normal cellular processes. However, many studies have shown that this pathway is altered in cancer cells and promotes the survival, proliferation, growth, metabolism, angiogenesis and metastasis of cancer [120]. For example, in HCC, the PI3K/Akt pathway activation promotes angiogenesis and EMT via exosomes and microRNA-32-5p [121]. The PI3K/Akt pathway activation also accounts for sorafenib resistance and induces multidrug resistance in HCC [122]. Using LY294002, a PI3K inhibitor, sorafenib resistance can be reversed in HCC [123].

The PI3K/Akt signaling pathway can regulate the glycolysis in HCC through the following mechanisms. Firstly, activation of the PI3K/Akt signaling pathway can induce the expression of GLUT1 and GLUT4 to increase the glucose uptake rate in cancer cells (Fig. 3) [124, 125]. It has been reported that the PI3K/Akt pathway can also promote the translocation of GLUT1 and GLLUT4 from the cytoplasm to the cell membrane $[126,127]$. Secondly, the PI3K/Akt pathway can regulate the activity or the expression of some glycolytic enzymes, such as HK2, PFK1 and PFK2. For example, activation of PI3K/Akt pathway can promote the binding of HK2 to VDAC in mitochondria and increase HK2 activity directly [128]. PI3K/Akt activation can also directly cause the phosphorylation and activation of PFK2, leading to increased production of F-2, 6-BP to further enhance PFK1 activity [129]. Thirdly, PI3K/Akt can indirectly regulate the expression of glycolytic enzymes by interacting and regulating the expression of AMPK and HIF-1 $\alpha[14,35]$. Fourthly, PI3K/Akt also activates the downstream regulator of the mammalian target of rapamycin (mTOR) to further activate HIF- $1 \alpha$, so as to promote aerobic glycolysis, angiogenesis and neovascularization in cancer cells [18].

\section{HIF-1a}

As mentioned above, because of the rapid proliferation and expansion of cancer cells, hypoxia is present in the core of tumor tissues. In 1992, Semenza et al. first reported the nuclear transcription factor induced by hypoxia in Hep3B HCC cell line, which was termed as HIF$1 \alpha$ and acted as an enhancer of erythropoietin (EPO) gene [130]. HIF-1 $\alpha$ can be stabilized by hypoxia and then can bind to the hypoxia responsive elements (HRE) of target genes' promoters, resulting in the transcription of related genes involved in overcoming hypoxic effects [49]. HIF-1 $\alpha$ plays a key role in the regulation of proliferation, glucose metabolism, angiogenesis, invasion and metastasis, and multidrug resistance in cancer cells [9]. HIF- $1 \alpha$ is commonly overexpressed in HCC patients, and the higher expression levels of HIF- $1 \alpha$ are correlated to poor prognosis. It has been reported that HIF-1 $\alpha$ can control the transcriptional expression of over 80 genes that are involved in glucose metabolism, cell survival, angiogenesis, invasion and metastasis [131, 132]. By inhibiting or interfering with the expression of HIF- $1 \alpha$, it is effective to inhibit the energy metabolism and growth of HCC.

As a key regulator of glycolytic metabolism in HCC, HIF- $1 \alpha$ activation also contributes to the regulation of the Warburg effect, mostly at the transcriptional level as follows. Firstly, as a transcription factor, HIF- $1 \alpha$ can promote the transcription of GLUT-1, thereby enhancing the glucose uptake for glycolysis [133]. Secondly, HIF-1 $\alpha$ can control the transcription of several glycolytic enzymes, including HK2, PFK1, PKM2, LDHA and glyceraldehyde-3phosphate dehydrogenase (GAPDH). By upregulating the expression of these genes, the glycolysis level is further enhanced [134]. Thirdly, HIF-1 $\alpha$ can promote the expression of pyruvate dehydrogenase kinase (PDK) to inhibits PDH activity, leading to the conversion of pyruvate into lactate [135]. Moreover, except for hypoxic stress, HIF-1 $\alpha$ can also be regulated by various signaling pathways, including PI3K/Akt/mTOR, Raf/MAPK and AMPK, causing glycolysis levels to accelerate (Fig. 3) [136].

\section{C-Myc}

c-Myc is the most common oncogene involved in human carcinogenesis, and takes part in the regulation of 
cell cycle, cellular survival, proliferation and metabolic reprogramming [137]. Genetic analyses have demonstrated that c-Myc over-expression is seen in up to $70 \%$ of viral and alcohol-related HCC [138]. Moreover, cMyc overexpression has been reported to cause liver tumors generation in mice with enhanced glycolysis levels [139]. Like HIF-1 $\alpha$, c-Myc is another vital oncogene involved in the Warburg effect in HCC.

The oncogene c-Myc is known to positively regulate the Warburg effect through the following mechanisms. Firstly, as a key transcription factor, c-Myc was first linked to glycolysis because it can transactivate and promote the expression of LDH just like HIF-1 $\alpha$ [140]. Secondly, c-Myc can also promote the expression of GLUT1, PKM2 and HK2 to promote the glycolysis flux $[135,141]$. When bound to the PKM2 promoter, c-Myc can not only induce PKM2 expression, but also promote the PKM2/PKM1 ratio to promote the survival of cancer cells. Besides, the nuclear PKM2 can also act as a coactivator of $\beta$-catenin to induce c-Myc expression in turn, resulting in a positive feedback loop to promote the sustained expression of glycolytic genes sustaining [142]. Thirdly, c-Myc can activate PDK1 in collaboration with HIF- $1 \alpha$, causing increased lactate production and the acidity of the extracellular environment [143]. Fourthly, c-Myc has been suggested to mediate the elevation of glutaminolysis in cancer cells by promoting both the glutamine uptake and glutamine catabolism, thereby maintaining the integrity in mitochondrial TCA cycle to promote the survival of cancer cells [144]. In addition, there is also close interaction between c-Myc and other signaling pathways and transcription factors, such as HIF- $1 \alpha, \beta$-catenin, JAK/STAT3 signaling pathway and ERK signaling pathway (Fig. 3) [141, 143, 144].

Based on the critical role of c-Myc in HCC carcinogenesis, it is obvious that c-Myc is another attractive target for the development of a novel therapy. Lin et al. used a small molecule inhibitor of c-Myc, which was 10 , 058-F4, to treat HCC cell lines, and the results showed that this molecule could inhibit the proliferation and enhance chemosensitivity of HCC cells to low-dose doxorubicin, 5-fluorouracil and cisplatin [145]. There is another small molecule compound CX3543 (also called Quarfloxin), which targets and inhibits Myc Gquadruplexes, is currently in phase II clinical trials for the treatment of neuroendocrine carcinomas [146].

\section{Noncoding RNAs}

Noncoding RNAs are groups of functional RNAs that cannot be transcribed into proteins, but instead take part in various biological processes to regulate gene transcription and translation. Noncoding RNAs are responsible for up to $98 \%$ of the whole genome's transcripts, and they includes microRNAs (miRNAs), long non- coding RNAs (Lnc-RNAs), small interfering RNAs (siRNAs) and small nuclear RNAs (snRNAs) [147]. Noncoding RNAs, especially miRNAs and Lnc-RNAs, have been found to regulate the Warburg effect, and mainly through the regulation of glycolytic enzymes expression or glycolysis related pathways [35].

The three rate-limiting enzymes in the glycolysis pathway can all be regulated by various noncoding RNAs (Table 1). The miR-34a for example is downregulated in metastatic HCC tissues, and has been reported to inhibit HCC glycolysis by directly targeting HK1, HK2, and glucose-6-phosphate isomerase (GPI) [153]. The miR$199 \mathrm{a}-5 \mathrm{p}$ is also down-regulated in HCC tissues, and is associated with the tumor size and prognosis of patient. The miR-199a-5p can be inhibited by HIF- $1 \alpha$, leading to the inhibition of HK2 expression and the disruption of liver metabolism [157]. The miR-139-5p was found to regulate HK1 and PFKFB3 expression to regulate glycolysis, proliferation, migration and invasion of $\mathrm{HCC}$ [152]. Moreover, by directly targeting HK2, miR-125b was found to downregulate glucose metabolism so as to relieve 5-FU resistance in HCC cells [154]. Some LncRNAs, such as Lnc-TUG1, have also been demonstrated to regulate HK2 expression through the TUG1/miR455-3p/AMPKb2 axis [156]. Furthermore, miR-520 can inhibit the expression of PFK1 through Tat-activating regulatory DNA-binding protein (TARDBP)-mediated regulation of glycolysis in HCC [160]. PKM2 can also be regulated by miRNAs and Lnc-RNAs, for example, miR122 is down-regulated in HCC tissues, therefore, overexpression of miR-122 in HCC cells can inhibit the expression of PKM2 to promote apoptosis and inhibit migration and invasion of Hep3B cells [161]. The miR491-5p also functions as a tumor suppressor in HCC by reducing PKM2 expression [164]. The miR-374b is also involved in reducing the expression of PKM2 by inhibiting the expression of hnRNPA1, which causes resensitization of sorafenib HCC cells [165]. The LncRNA LINC01554 is often downregulated in HCC, and it's revealed that LINC01554 promotes the degradation of PKM2 through Akt/mTOR signaling pathway [163]. Moreover, a circular RNA, circMAT2B can also increase the expression levels of PKM2 through the regulation of the miR-338-3p [162].

Other key proteins, such as GLUT1 and LDHA are also regulated by noncoding RNAs in HCC, leading to changes of glucose uptake and lactate production levels. For example, miR-342-3p, miR-455-5p and miR-505 are all down-regulated in HCC tissues, and they have been reported to be able to decrease glycolysis by inhibiting GLUT1 expression through insulin growth factor receptor 1 (IGF-1R) or the PI3K/AKT pathway [148-150]. Whereas Lnc- HOTAIR was found to promote glycolysis by upregulating GLUT1 expression through mTOR 
Table 1 Noncoding RNAs and their targets in aerobic glycolysis in HCC

\begin{tabular}{|c|c|c|c|c|}
\hline Target & ncRNA & In vivo or in vitro & Involvement of other factors & Reference \\
\hline \multirow[t]{4}{*}{ GLUT } & miR-342-3p & both & PI3K/AKT & [148] \\
\hline & miR-505 & both & IGF-1R & [149] \\
\hline & miR-455-5p & both & IGF-1R/AKT & [150] \\
\hline & IncRNA HOTAIR & both & mTOR & [151] \\
\hline \multirow[t]{6}{*}{ HK2、HK1 } & miR-139-5p & both & ETS1 & [152] \\
\hline & miR-34a & in vitro & p53 & [153] \\
\hline & miR-125b & both & - & {$[154,155]$} \\
\hline & Lnc-TUG1 & in vitro & TUG1/miR-455-3p/AMPKß2 & [156] \\
\hline & miR-199a-5p & both & PKM2 & {$[157,158]$} \\
\hline & miR-885-5p & both & HIF-1a & [159] \\
\hline \multirow[t]{2}{*}{ PFK1、PFKFB3 } & miR-139-5p & both & ETS1 & [152] \\
\hline & miR-520 & both & TARDBP & [160] \\
\hline \multirow[t]{5}{*}{ PKM2 } & miR-122 & both & - & [161] \\
\hline & circMAT2B & both & miR-338-3p & [162] \\
\hline & IncRNA LINC01554 & both & Akt/mTOR & [163] \\
\hline & miR-491-5p & both & - & [164] \\
\hline & MiR-374b & in vitro & hnRNPA1 & [165] \\
\hline \multirow[t]{2}{*}{ LDHA } & miR-142-3p & both & - & [166] \\
\hline & miR-34a & both & - & {$[167,168]$} \\
\hline \multirow[t]{2}{*}{ HIF-1A } & miR-199a-5p & both & - & [169] \\
\hline & miR-3662 & both & ERKJJNK & [170] \\
\hline \multirow[t]{2}{*}{ PI3K/Akt/mTOR } & miR-125a & in vitro & - & [171] \\
\hline & miR-7 & both & - & [172] \\
\hline \multirow[t]{2}{*}{ c-myc/STAT3 } & miR-23a & in vitro & PEPCK & [173] \\
\hline & miR-129-5p & both & PDK4 & [174] \\
\hline JAK/STAT & miR-196a /b & both & SOCS2 & [175] \\
\hline PPARY & IncRNA Ftx & both & - & [176] \\
\hline mTOR/TCF7L2 & IncRNA MALAT1 & in vitro & mTOR & [177] \\
\hline
\end{tabular}

mediated pathway [151]. Furthermore, miR-142-3p and miR-34a have been found to target LDHA to suppress aerobic glycolysis and cell proliferation in HCC [166-168].

Noncoding RNAs can also regulate glycolysis levels in HCC by targeting various signaling pathways involved in glycolysis. For example, HIF- $1 \alpha$, the key regulator in response to hypoxia, can be directly regulated by miR199ab-5p and miR-3662 to inhibit the Warburg effect in HCC $[169,170]$. While the miR-125a and miR-7 can suppress HCC progression by inhibiting the PI3K/Akt pathway $[171,172]$. The c-Myc is the target of miR-1295p and miR-23a [174, 178], and mTOR is the target of lncRNA MALAT1 [177], and PPAR- $\gamma$ is the target of lncRNA Ftx [176]. Through the interaction with the STAT3 pathway, miR-196a or miR-196b is able to suppress cell proliferation and glycolysis, and induced apoptosis in HCC cells [175].

\section{Discussions and expectations}

The metabolic shift from OXPHOS to aerobic glycolysis is not only a hallmark of HCC, but also provides many potential targets for exploitation in in HCC therapy. After an appreciation of the important roles of aerobic glycolysis in HCC, an understanding of the regulatory mechanisms involved will enable researchers the opportunity to develop novel therapeutic methods. These may include: (1) targeting the three rate-limiting enzymes in glycolysis to inhibit the aerobic glycolysis process directly. (2) Targeting the GLUTs or LDHA to inhibit the glucose uptake or lactate levels. (3) Targeting the regulatory factors and signaling pathways involved in glycolysis to regulate glycolysis indirectly. Moreover, sorafenib as a target drug for $\mathrm{HCC}$, was found to induce drug resistance which includes the participance of enhanced glycolysis. If combined with glycolysis targeting drugs, such as 2-DG, the anti-cancer effect of sorafenib may 
be enhanced, and sorafenib resistance can also be reversed [91].

\section{Therapeutic agents that target glycolysis}

Currently, there are some widely-used agents that can target on HK2, PFK1 or PKM2 to inhibit glycolysis. For example, 2-DG is an analog of glucose, and it can be catalyzed by HK2 into 2-deoxy-D-glucose-6-phosphate (2-DG-6P), which is different from G-6-P and can noncompetitively inhibit the activity of HK2 [5, 35]. When 2-DG was given alone in HCC, it was reported to suppress the growth, metastasis and invasion of HCC cells, and the combination treatment of 2-DG and other chemotherapy drugs, such as sorafenib, 2aminophenoxazine-3-one (Phx-3), and metformin, can also enhance the anticancer effect of them on HCC [179-181]. The 3-bromopyruvate (3-BP) is a different type of HK2 inhibitor with the ability to inhibit HK2 activity directly, so as to strongly suppress the glycolysis process. Many in vitro and in vivo studies have verified the anti-HCC effects of 3-BP, and recently it has been approved by the FDA to treat HCC and intrahepatic cholangiocarcinoma [182]. The 3-(3-pyridinyl)-1-(4-pyridinyl)-2-propen-1-one (3-PO) is a selective PFKFB3 inhibitor and has been found to inhibit the growth and glycolysis of lung cancer and breast cancer both in vivo and in vitro [183]. Moreover, there are also some effective inhibitors of PKM2, such as TT-232(CAP-232) and shikonin, that can inhibit the growth and induce apoptosis of cancer cells [184-186].

However, although some of these drugs targeting glycolysis are currently undergoing phase I or II clinical trials, their clinical application is far from secure. Besides, the design of metabolic targeted therapeutic strategies should also evaluate the tumor heterogeneity and interaction with the micro-environment carefully, giving rise to the difficulties in development of effective drugs. Therefore, the exploration of new agents, especially traditional Chinese medicine monomers, such as genistein, 15d-PGJ2, quercetin, and oleanolic acid, to test for antiglycolysis effects are urgently needed with the help of proteomics and metabolomics analyses and genomescale metabolic models [26, 187-190].

\section{Anti-VEGFR or anti-PD-1/PD-L1 agents}

As mentioned above, the inducing of sorafenib resistance in HCC treatment is correlated with the enhanced aerobic glycolysis levels, which limits the application and availability of sorafenib. Therefore, recently, there are some other agents, which are also receptor tyrosine kinase (RTK) inhibitors as sorafenib that can inhibit VEGFR activities and angiogenesis of HCC, having been used in several phase III trials as first-line or second-line chemotherapy for HCC to determine whether these agents are superior to sorafenib. For example, lenvatinib has been tested as first line treatment in the REFLECT trial, and was shown to be non-inferior to sorafenib (overall survival) [191]. While regorafenib, cabozantinib, and ramucirumab were shown to be superior to placebo in HCC patients failing sorafenib treatment [192, 193]. A phase II trial that combined bevacizumab (VEGFR inhibitor) and erlotinib (EGFR inhibitor) was also designed to compare the effect as first-line treatment for advanced HCC patients to sorafenib alone, and the results showed that there was no difference in efficacy between the bevacizumab + erlotinib group and sorafenib alone, while bevacizumab + erlotinib showed a better safety and tolerability [194]. Therefore, these anti-VEGFR agents are considered as "preferred regimens" as first line treatment for advanced HCC [195].

The programmed death-1 (PD-1) is a famous immune checkpoint, which can be activated by its ligands, such as PD-L1, leading to the suppression of immune response. During carcinogenesis, cancer cells take advantage of the PD-L1/PD-1 system to evade immune supervision. It has been reported that compared with PD-L1-negative HCC patients, PD-L1-positive HCC patients showed significantly worse overall survival [196]. Blocking PD-1 or PD-L1 has become a therapeutic method for HCC treatment, such as atezolizumab, pembrolizumab and nivolumab. Most recently, Finn and his colleagues conducted a phase III IMbrave150 trial, which compared the combination of bevacizumab and atezolizumab (targeting programmed cell death ligand 1, PD-L1) against standard sorafenib treatment in first line treatment for advanced HCC. The current results showed that the combination can increase the progression-free survival and overall survival than patients who received sorafenib alone [197-199]. Therefore, the NCCN guideline (2020) also included the combination of bevacizumab and atezolizumab as another first-line standard treatment for unresectable HCC just as sorafenib.

\section{Role of androgen receptors and induction of glycolysis in $\mathrm{HCC}$}

$\mathrm{HCC}$ is a considered as a male-dominant cancer. Zhang et al. reported in 2018 that androgen receptor (AR) was overexpressed in the nucleus of $37 \%$ of HCC tumors, which may be correlated to the advanced disease stage and poor survival of HCC patients [200]. The role of AR expression in HCC has been investigated by many researchers. Wang et al. found that AR can promote HBV viral RNA expression, which favors HBV-driven hepatocarcinogenesis [201]. Ma et al. found that AR knockout reduced liver tumors number and burden in mice, suggesting that AR is necessary for full cancer development. The activation of AR may lead to the activation of 
androgen response elements, and then the transcription of target genes, including Src, EGFR, ERK, HIF-1 $\alpha$, and CREB [202].

AR has also been found to induce glycolysis in HCC. Sun et al. found that AR expression is positively correlated with HK2 levels, and then promoted HCC growth by enhancing HK2-mediated glycolysis through the regulation of PKA/CREB [203]. Moreover, Zhang et al. demonstrated that AR can crosstalk with mTOR, which may also help the activation of glycolysis through mTOR mediated pathway [200].

Antiandrogen and anti-AR agents, such as bicalutamide and enzalutamide, are therefore considered as therapeutic methods for HCC treatment as well. Unfortunately, early clinical trials on anti-androgen and bicalutamide therapies in liver cancer met with disappointing results, producing no apparent clinical benefits $[204,205]$. But, the combination of anti-AR and other chemotherapy agents, such as sorafenib, may be a new approach for HCC treatment. For example, Xiao et al. reported that found that AR can re-sensitize HCC to sorafenib through AR/miR-520f-3p/SOX9 signaling [206]. Jiang et al. observed that sorafenib-induced apoptosis can be enhanced by AR inhibition in HCC cell lines [207]. Wang et al. also reported that sorafenib inhibited AR activation induced by $\mathrm{HBx}$ [208]. Taken together, based on the role of AR on HCC growth and glycolysis, AR is still a promising target for HCC treatment.

\section{Effects of fasting on glycolysis regulating genes and apoptosis}

Recently years, fasting/starvation (16-60 h) has also been tested in some clinical trials for cancer treatment because it has been found that fasting can reduce the side effects associated to high dose chemotherapy in various cancer patients, and protect normal cells from injuries (NCT01304251, NCT01175837, NCT00936364, NCT01175837) [209]. However, the molecular mechanisms how fasting suppresses cancer cells remain unknown.

Liver is the primary organ for glucose metabolism. During fasting, approximately $80 \%$ of endogenous glucose is produced through gluconeogenesis, which is actually a reverse pathway of glycolysis, to adapt to stress conditions [210]. Valentina Sukonina et al. found that $16 \mathrm{~h}$ of fasting could induce the elevation of glycolysis in mice, with enhanced glucose uptake levels and impaired OXPHOS, mainly through FOXK1 and FOXK2 mediated glycolytic gene expression, including HK2, PFKM, PKM2 and LDHA [211]. However, in cancer cells, which are highly depended on glucose for energy supply, the situation is totally opposite. It has been reported that deprivation of glucose (fasting) impairs glycolysis and the pentose phosphate pathway, induces oxidative stress because of enhanced production of reactive oxygen species (ROS), resulting in the redox imbalance and then cancer cell death [106]. Moreover, Bianchi et al. reported that fasting could induce anti-Warburg effect in colon cancer models, including the downregulation of HK2, PFK, PKM2, and LDH expression. Moreover, they also found that because of the increase in mitochondrial respiration, fasting can also promote apoptosis in colon cancer cell [212]. Grasl-Kraupp have also reported in 1994 that fasting could eliminate preneoplastic cells through apoptosis, thereby inhibiting the carcinogenesis in rat liver [213]. The mechanisms how fasting induces apoptosis in HCC cells may include: (1) fasting improves OXPHOS in mitochondria, which then enhances the electron transport chain function and the production of ROS, leading to the induction of apoptosis [212]. (2) Fasting induces inducible nitric oxide synthase and interferon- $\gamma$ production, so as to increase ROS production and induce apoptosis [214].

In conclusion, owing to the functional role of fasting on HCC glycolysis and apoptosis, fasting is also a potential therapeutic approach for HCC treatment, and we can pay more attention to it.

\section{Role of EMT in HCC}

As mentioned above, EMT is responsible for sorafenib resistance, as well as HCC angiogenesis and metastasis. EMT of cancer cells indicates that epithelial cells lose their cell-cell adhesions and apicobasal polarity, and acquire more mesenchymal and invasive/metastatic phenotype [215]. EMT also plays important role in the aerobic process in HCC. Zhang et al. found that the depletion of mitochondrial fusion protein mitofusin-1 (MFN1) triggered the EMT of HCC and modulated HCC metastasis by metabolic shift from aerobic glycolysis to oxidative phosphorylation [216]. EMT also contributes to the increased population of cancer stem-like cells (CSCs) associated with $\mathrm{Wnt} / \beta$-catenin activation, and can lead to tumor heterogeneity and therapeutic resistance [217]. In liver tissues, hepatocytes generally harbor the rapid cellular proliferation under both normal and inflammatory conditions. It still remains unknown whether the origin of HCC is from the CSCs or differentiated hepatocytes [215].

The hepatic stellate cells (HSCs) are kinds of mesenchymal cells in liver tissues, and can transdifferentiate into myofibroblasts in response to stimulus. Duran et al. reported that p62/SQSTM1, which can interact with the components of the mTORC1 complex during autophagy process, can negatively control HSCs activation through binding to the vitamin D receptor (VDR) [218]. Through acting as carcinoma-associated fibroblasts (CAFs), HSCs undergo EMT both in liver fibrosis, cirrhosis and HCC, leading to the tumor formation and development [219]. 
Taken together, the EMT process and the myofibroblasts in liver tissues are another therapeutic target for HCC treatment.

\section{Conclusions}

In conclusion, the aerobic glycolysis plays important roles in the progression of HCC, including proliferation, immune evasion, invasion and metastasis, angiogenesis, and drug resistance. Via targeting key factors included in aerobic glycolysis, such as the inhibition of enzymes HK2, PFK or PKM2, and the regulatory pathways. Represent potential new therapeutic approaches for the treatment of HCC.

\section{Acknowledgements}

We thank the International Science Editing (http://www.

internationalscienceediting.com) for editing this manuscript.

\section{Authors' contributions}

Conceptualization, JF, JL, LW, QY, and JJ; writing —original draft preparation, JF; writing — review and editing, JW and WD; visualization, JF; supervision, CG; funding acquisition, JW and CG. The authors read and approved the final manuscript.

\section{Funding}

This study was supported by: (1) the National Natural Science Foundation of China (grant number: 81670472); (2) the Natural Science Foundation of Shanghai (grant number: 19ZR1447700); (3) the Health System Innovation Project of Shanghai Putuo Science and Technology Commission (grant number: PTKWWS201801, PTKWWS201903); (4) WBN Hepatology Research Fund of China Hepatitis Prevention and Treatment Foundation (grant number: CFHP(2019031).

\section{Availability of data and materials}

Not applicable.

\section{Ethics approval and consent to participate}

Not applicable.

\section{Consent for publication}

Not applicable.

\section{Competing interests}

The authors declare that they have no competing interests.

\section{Author details}

'Department of Gastroenterology, Putuo People's Hospital, Tongji University School of Medicine, number 1291, Jiangning road, Putuo, Shanghai 200060 , China. 'Department of Gastroenterology, Shanghai Tenth People's Hospital, Tongji University School of Medicine, number 301, Middle Yanchang road, Jing'an, Shanghai 200072, China. ${ }^{3}$ Department of Gastroenterology, Zhongshan Hospital of Fudan University, Shanghai 200032, China. ${ }^{4}$ Shanghai Institute of Liver Diseases, Zhongshan Hospital of Fudan University, Shanghai 200032, China. ${ }^{5}$ Shanghai Tongren Hospital, Shanghai Jiaotong University School of Medicine, Shanghai 200336, China.

Received: 9 May 2020 Accepted: 25 June 2020

Published online: 06 July 2020

\section{References}

1. Bray F, Ferlay J, Soerjomataram I, Siegel RL, Torre LA, Jemal A. Global cancer statistics 2018: GLOBOCAN estimates of incidence and mortality worldwide for 36 cancers in 185 countries. CA Cancer J Clin. 2018:68:394-424. https:// doi.org/10.3322/caac.21492..

2. El Kassas M, Tawheed A, Eltabbakh M, Kaseb A. Hepatitis C antiviral therapy in patients with successfully treated hepatocellular carcinoma: dancing with wolves. J Hepatocell Carcinoma. 2019;6:183-91. https://doi.org/10.2147/JHC. S206668.

3. Stavraka C, Rush H, Ross P. Combined hepatocellular cholangiocarcinoma (cHCC-CC): an update of genetics, molecular biology, and therapeutic interventions. J Hepatocell Carcinoma. 2019;6:11-21. https://doi.org/10.2147/ JHC.S159805.

4. Duan J, Wu Y, Liu J, Zhang J, Fu Z, Feng T, Liu M, Han J, Li Z, Chen S. Genetic biomarkers for hepatocellular carcinoma in the era of precision medicine. J Hepatocell Carcinoma. 2019;6:151-66. https://doi.org/10.2147/ JHC.S224849.

5. Lee $\mathrm{M}, \mathrm{Ko} \mathrm{H}$, Yun M. Cancer metabolism as a mechanism of treatment resistance and potential therapeutic target in hepatocellular carcinoma. Yonsei Med J. 2018;59:1143-9. https://doi.org/10.3349/ymj.2018.59.10.1143.

6. Sia D, Villanueva A, Friedman SL, Llovet JM. Liver Cancer cell of origin, molecular class, and effects on patient prognosis. Gastroenterology. 2017; 152:745-61. https://doi.org/10.1053/j.gastro.2016.11.048

7. Connell LC, Harding JJ, Abou-Alfa GK. Advanced hepatocellular Cancer: the current state of future research. Curr Treat Options in Oncol. 2016;17:43. https://doi.org/10.1007/s11864-016-0415-3.

8. Azim HA, Omar A, Atef H, Zawahry H, Shaker MK, Abdelmaksoud AK, EzzElarab M, Abdel-Rahman O, Ismail M, Kassem L, Waked I. Sorafenib plus tegafur-uracil (UFT) versus sorafenib as first line systemic treatment for patients with advanced stage HCC: a phase II trial (ESLC01 study). J Hepatocell Carcinoma. 2018;5:109-19. https://doi.org/10.2147/JHC.S169285.

9. Mendez-Blanco C, Fondevila F, Garcia-Palomo A, Gonzalez-Gallego J, Mauriz JL. Sorafenib resistance in hepatocarcinoma: role of hypoxiainducible factors. Exp Mol Med. 2018;50:134. https://doi.org/10.1038/ s12276-018-0159-1.

10. Llovet JM, Ricci S, Mazzaferro V, Hilgard P, Gane E, Blanc JF, de Oliveira AC, Santoro A, Raoul JL, Forner A, Schwartz M, Porta C, Zeuzem S, et al. Sorafenib in advanced hepatocellular carcinoma. N Engl J Med. 2008;359: 378-90. https://doi.org/10.1056/NEJMoa0708857.

11. Niu L, Liu L, Yang S, Ren J, Lai PBS, Chen GG. New insights into sorafenib resistance in hepatocellular carcinoma: responsible mechanisms and promising strategies. Biochim Biophys Acta Rev Cancer. 1868;2017:564-70. https://doi.org/10.1016/j.bbcan.2017.10.002.

12. Hanahan D, Weinberg RA. Hallmarks of cancer: the next generation. Cell. 2011:144:646-74. https://doi.org/10.1016/j.cell.2011.02.013.

13. Schwartz L, Supuran CT, Alfarouk KO. The Warburg effect and the hallmarks of Cancer. Anti Cancer Agents Med Chem. 2017;17:164-70. https://doi.org/ 10.2174/1871520616666161031143301.

14. Koppenol WH, Bounds PL, Dang CV. Otto Warburg's contributions to current concepts of cancer metabolism. Nat Rev Cancer. 2011;11:325-37. https://doi.org/10.1038/nrc3038.

15. Mathupala SP, Ko YH, Pedersen PL. Hexokinase-2 bound to mitochondria: cancer's stygian link to the "Warburg effect" and a pivotal target for effective therapy. Semin Cancer Biol. 2009;19:17-24. https://doi.org/10.1016/ j.semcancer.2008.11.006.

16. Vaupel $\mathrm{P}$, Schmidberger $H_{1}$ Mayer A. The Warburg effect: essential part of metabolic reprogramming and central contributor to cancer progression. Int J Radiat Biol. 2019;95:912-9. https://doi.org/10.1080/09553002.2019. 1589653.

17. Gatenby RA, Gawlinski ET. The glycolytic phenotype in carcinogenesis and tumor invasion: insights through mathematical models. Cancer Res. 2003;63: 3847-54.

18. Bhattacharya B, Mohd Omar MF, Soong R. The Warburg effect and drug resistance. Br J Pharmacol. 2016;173:970-9. https://doi.org/10.1111/bph. 13422.

19. Bannasch P, Ribback S, Su Q, Mayer D. Clear cell hepatocellular carcinoma: origin, metabolic traits and fate of glycogenotic clear and ground glass cells. Hepatobiliary Pancreat Dis Int. 2017;16:570-94. https://doi.org/10.1016/ S1499-3872(17)60071-7.

20. Enzo E, Santinon G, Pocaterra A, Aragona M, Bresolin S, Forcato M, Grifoni D Pession A, Zanconato F, Guzzo G, Bicciato S, Dupont S. Aerobic glycolysis tunes YAP/TAZ transcriptional activity. EMBO J. 2015;34:1349-70. https://doi. org/10.15252/embj.201490379.

21. Shuch B, Linehan WM, Srinivasan R. Aerobic glycolysis: a novel target in kidney cancer. Expert Rev Anticancer Ther. 2013;13:711-9. https://doi.org/10. 1586/era.13.57.

22. Xiang J, Hu Q, Qin Y, Ji S, Xu W, Liu W, Shi S, Liang C, Liu J, Meng Q, Liang $\mathrm{D}, \mathrm{Ni} \mathrm{Q}, \mathrm{Xu}$ J, et al. TCF7L2 positively regulates aerobic glycolysis via the 
EGLN2/HIF-1alpha axis and indicates prognosis in pancreatic cancer. Cell Death Dis. 2018;9:321. https://doi.org/10.1038/s41419-018-0367-6.

23. Feinberg T, Herbig J, Kohl I, Las G, Cancilla JC, Torrecilla JS, Ilouze M, Haick $\mathrm{H}$, Peled N. Cancer metabolism: the volatile signature of glycolysis-in vitro model in lung cancer cells. J Breath Res. 2017;11:016008. https://doi.org/10. 1088/1752-7163/aa51d6.

24. Yuan LW, Yamashita H, Seto Y. Glucose metabolism in gastric cancer: the cutting-edge. World J Gastroenterol. 2016;22:2046-59. https://doi.org/10. 3748/wjg.v22.i6.2046

25. Ciccarese C, Santoni M, Massari F, Modena A, Piva F, Conti A, Mazzucchelli R, Cheng L, Lopez-Beltran A, Scarpelli M, Tortora G, Montironi R. Metabolic alterations in renal and prostate Cancer. Curr Drug Metab. 2016;17:150-5. https://doi.org/10.2174/1389200216666151015112356.

26. Li S, Li J, Dai W, Zhang Q, Feng J, Wu L, Liu T, Yu Q, Xu S, Wang W, Lu X, Chen $K$, Xia Y, et al. Genistein suppresses aerobic glycolysis and induces hepatocellular carcinoma cell death. Br J Cancer. 2017;117:1518-28. https:// doi.org/10.1038/bjc.2017.323.

27. Beyoglu D, Imbeaud S, Maurhofer O, Bioulac-Sage P, Zucman-Rossi J, Dufour JF, Idle JR. Tissue metabolomics of hepatocellular carcinoma: tumor energy metabolism and the role of transcriptomic classification. Hepatology. 2013;58:229-38. https://doi.org/10.1002/hep.26350.

28. Bustamante E, Pedersen PL. High aerobic glycolysis of rat hepatoma cells in culture: role of mitochondrial hexokinase. Proc Natl Acad Sci U S A. 1977;74: 3735-9. https://doi.org/10.1073/pnas.74.9.3735.

29. Gwangwa MV, Joubert AM, Visagie MH. Crosstalk between the Warburg effect, redox regulation and autophagy induction in tumourigenesis. Cell Mol Biol Lett. 2018;23:20. https://doi.org/10.1186/s11658-018-0088-y.

30. Yin $\mathrm{PH}$, Wu CC, Lin JC, Chi CW, Wei YH, Lee HC. Somatic mutations of mitochondrial genome in hepatocellular carcinoma. Mitochondrion. 2010; 10:174-82. https://doi.org/10.1016/j.mito.2009.12.147.

31. Hsu CC, Lee HC, Wei YH. Mitochondrial DNA alterations and mitochondrial dysfunction in the progression of hepatocellular carcinoma. World $J$ Gastroenterol. 2013;19:8880-6. https://doi.org/10.3748/wjg.v19.i47.8880

32. Li Y, Lin S, Li L, Tang Z, Hu Y, Ban X, Zeng T, Zhou Y, Zhu Y, Gao S, Deng W, Zhang $X$, Xie D, et al. PDSS2 deficiency induces Hepatocarcinogenesis by decreasing mitochondrial respiration and reprogramming glucose metabolism. Cancer Res. 2018;78:4471-81. https://doi.org/10.1158/0008-5472.CAN-17-2172.

33. Bai J, Liu Z, Liu J, Zhang S, Tian Y, Zhang Y, Ren L, Kong D. Mitochondria metabolic study guided by proteomics analysis in hepatocellular carcinoma cells surviving long-term incubation with the highest dose of sorafenib. Aging. 2019;11:12452-75. https://doi.org/10.18632/aging.102582.

34. Cheng G, Zielonka J, Dranka BP, McAllister D, Mackinnon AC Jr, Joseph J, Kalyanaraman B. Mitochondria-targeted drugs synergize with 2deoxyglucose to trigger breast cancer cell death. Cancer Res. 2012;72:263444. https://doi.org/10.1158/0008-5472.CAN-11-3928.

35. Shang RZ, Qu SB, Wang DS. Reprogramming of glucose metabolism in hepatocellular carcinoma: Progress and prospects. World J Gastroenterol. 2016;22:9933-43. https://doi.org/10.3748/wjg.v22.i45.9933

36. Ganapathy-Kanniappan S. Linking tumor glycolysis and immune evasion in cancer: emerging concepts and therapeutic opportunities. Biochim Biophys Acta Rev Cancer. 1868;2017:212-20. https://doi.org/10.1016/j.bbcan.2017.04.002.

37. Yang DQ, Freund DM, Harris BR, Wang D, Cleary MP, Hegeman AD. Measuring relative utilization of aerobic glycolysis in breast cancer cells by positional isotopic discrimination. FEBS Lett. 2016;590:3179-87. https://doi. org/10.1002/1873-3468.12360.

38. Lis P, Dylag M, Niedzwiecka K, Ko YH, Pedersen PL, Goffeau A, Ulaszewski S. The HK2 dependent "Warburg effect" and mitochondrial oxidative phosphorylation in Cancer: targets for effective therapy with 3Bromopyruvate. Molecules. 2016;21. https://doi.org/10.3390/ molecules21121730.

39. DeWaal D, Nogueira V, Terry AR, Patra KC, Jeon SM, Guzman G, Au J, Long $\mathrm{CP}$, Antoniewicz MR, Hay N. Hexokinase-2 depletion inhibits glycolysis and induces oxidative phosphorylation in hepatocellular carcinoma and sensitizes to metformin. Nat Commun. 2018;9:446. https://doi.org/10.1038/ s41467-017-02733-4

40. Gong L, Cui Z, Chen P, Han H, Peng J, Leng X. Reduced survival of patients with hepatocellular carcinoma expressing hexokinase II. Med Oncol. 2012;29: 909-14. https://doi.org/10.1007/s12032-011-9841-z.

41. Xu S, Herschman HR. A tumor agnostic therapeutic strategy for hexokinase 1-null/hexokinase 2-positive cancers. Cancer Res. 2019;79:5907-14. https:// doi.org/10.1158/0008-5472.CAN-19-1789.
42. Zhang T, Zhu X, Wu H, Jiang K, Zhao G, Shaukat A, Deng G, Qiu C. Targeting the ROS/PI3K/AKT/HIF-1alpha/HK2 axis of breast cancer cells: combined administration of Polydatin and 2-Deoxy-d-glucose. J Cell Mol Med. 2019;23:3711-23. https://doi.org/10.1111/jcmm.14276.

43. Liu R, Li Y, Tian L, Shi H, Wang J, Liang Y, Sun B, Wang S, Zhou M, Wu L, Nie J, Lin B, Tang S, et al. Gankyrin drives metabolic reprogramming to promote tumorigenesis, metastasis and drug resistance through activating betacatenin/c-Myc signaling in human hepatocellular carcinoma. Cancer Lett. 2019;443:34-46. https://doi.org/10.1016/j.canlet.2018.11.030

44. Hanlon MM, Rakovich T, Cunningham CC, Ansboro S, Veale DJ, Fearon U, McGarry T. STAT3 mediates the differential effects of Oncostatin M and TNFalpha on RA synovial fibroblast and endothelial cell function. Front Immunol. 2019;10:2056. https://doi.org/10.3389/fimmu.2019.02056.

45. Li W, Qiu Y, Hao J, Zhao C, Deng X, Shu G. Dauricine upregulates the chemosensitivity of hepatocellular carcinoma cells: role of repressing glycolysis via miR-199a:HK2/PKM2 modulation. Food Chem Toxicol. 2018; 121:156-65. https://doi.org/10.1016/.ffct.2018.08.030.

46. Ludvik AE, Pusec CM, Priyadarshini M, Angueira AR, Guo C, Lo A, Hershenhouse KS, Yang GY, Ding X, Reddy TE, Lowe WL Jr, Layden BT. HKDC1 is a novel hexokinase involved in whole-body glucose use. Endocrinology. 2016;157:3452-61. https://doi.org/10.1210/en.2016-1288.

47. Zhang Z, Huang S, Wang H, Wu J, Chen D, Peng B, Zhou Q. High expression of hexokinase domain containing 1 is associated with poor prognosis and aggressive phenotype in hepatocarcinoma. Biochem Biophys Res Commun. 2016;474:673-9. https://doi.org/10.1016/j.bbrc.2016.05.007.

48. Kanai S, Shimada T, Narita T, Okabayashi K. Phosphofructokinase-1 subunit composition and activity in the skeletal muscle, liver, and brain of dogs. J Vet Med Sci. 2019:81:712-6. https://doi.org/10.1292/jvms.19-0049.

49. Al Hasawi N, Alkandari MF, Luqmani YA. Phosphofructokinase: a mediator of glycolytic flux in cancer progression. Crit Rev Oncol Hematol. 2014;92:31221. https://doi.org/10.1016/j.critrevonc.2014.05.007.

50. Zancan P, Almeida FV, Faber-Barata J, Dellias JM, Sola-Penna M. Fructose2,6-bisphosphate counteracts guanidinium chloride-, thermal-, and ATPinduced dissociation of skeletal muscle key glycolytic enzyme 6phosphofructo-1-kinase: a structural mechanism for PFK allosteric regulation. Arch Biochem Biophys. 2007:467:275-82. https://doi.org/10.1016/j.abb.2007. 08.032 .

51. Bartrons R, Rodriguez-Garcia A, Simon-Molas H, Castano E, Manzano A, Navarro-Sabate A. The potential utility of PFKFB3 as a therapeutic target. Expert Opin Ther Targets. 2018;22:659-74. https://doi.org/10.1080/14728222. 2018.1498082

52. Wu Z, Wu J, Zhao Q, Fu S, Jin J. Emerging roles of aerobic glycolysis in breast cancer. Clin Transl Oncol. 2019. https://doi.org/10.1007/s12094-01902187-8.

53. Yalcin A, Telang S, Clem B, Chesney J. Regulation of glucose metabolism by 6-phosphofructo-2-kinase/fructose-2,6-bisphosphatases in cancer. Exp Mol Pathol. 2009:86:174-9. https://doi.org/10.1016/j.yexmp.2009.01.003.

54. Li S, Dai W, Mo W, Li J, Feng J, Wu L, Liu T, Yu Q, Xu S, Wang W, Lu X, Zhang Q, Chen K, et al. By inhibiting PFKFB3, aspirin overcomes sorafenib resistance in hepatocellular carcinoma. Int J Cancer. 2017;141:2571-84. https://doi.org/10.1002/ijc.31022.

55. Yalcin A, Clem BF, Imbert-Fernandez Y, Ozcan SC, Peker S, O'Neal J, Klarer AC, Clem AL, Telang S, Chesney J. 6-Phosphofructo-2-kinase (PFKFB3) promotes cell cycle progression and suppresses apoptosis via Cdk1mediated phosphorylation of p27. Cell Death Dis. 2014;5:e1337. https://doi. org/10.1038/cddis.2014.292.

56. Peng F, Li Q, Sun JY, Luo Y, Chen M, Bao Y. PFKFB3 is involved in breast cancer proliferation, migration, invasion and angiogenesis. Int J Oncol. 2018; 52:945-54. https://doi.org/10.3892/ijo.2018.4257.

57. Minchenko OH, Tsuchihara K, Minchenko DO, Bikfalvi A, Esumi $H$. Mechanisms of regulation of PFKFB expression in pancreatic and gastric cancer cells. World J Gastroenterol. 2014;20:13705-17. https://doi.org/10. 3748/wjg.v20.i38.13705.

58. Bobarykina AY, Minchenko DO, Opentanova IL, Moenner M, Caro J, Esumi H, Minchenko OH. Hypoxic regulation of PFKFB-3 and PFKFB-4 gene expression in gastric and pancreatic cancer cell lines and expression of PFKFB genes in gastric cancers. Acta Biochim Pol. 2006;53:789-99.

59. Han J, Meng Q, Xi Q, Wang H, Wu G. PFKFB3 was overexpressed in gastric cancer patients and promoted the proliferation and migration of gastric cancer cells. Cancer Biomark. 2017;18:249-56. https://doi.org/10.3233/CBM160143. 
60. van Niekerk G, Engelbrecht AM. Role of PKM2 in directing the metabolic fate of glucose in cancer: a potential therapeutic target. Cell Oncol (Dordr). 2018:41:343-51. https://doi.org/10.1007/s13402-018-0383-7.

61. Anastasiou D, Yu Y, Israelsen WJ, Jiang JK, Boxer MB, Hong BS, Tempel W, Dimov S, Shen M, Jha A, Yang H, Mattaini KR, Metallo CM, et al. Pyruvate kinase $\mathrm{M} 2$ activators promote tetramer formation and suppress tumorigenesis. Nat Chem Biol. 2012;8:839-47. https://doi.org/10.1038/ nchembio.1060

62. Azoitei N, Becher A, Steinestel K, Rouhi A, Diepold K, Genze F, Simmet T, Seufferlein T. PKM2 promotes tumor angiogenesis by regulating HIF-1alpha through NF-kappaB activation. Mol Cancer. 2016;15:3. https://doi.org/10. 1186/s12943-015-0490-2

63. Luo W, Hu H, Chang R, Zhong J, Knabel M, O'Meally R, Cole RN, Pandey A, Semenza GL. Pyruvate kinase M2 is a PHD3-stimulated coactivator for hypoxia-inducible factor 1. Cell. 2011;145:732-44. https://doi.org/10.1016/j. cell.2011.03.054.

64. Park SH, Ozden O, Liu G, Song HY, Zhu Y, Yan Y, Zou X, Kang HJ, Jiang H, Principe DR, Cha YI, Roh M, Vassilopoulos A, et al. SIRT2-mediated Deacetylation and Tetramerization of pyruvate kinase directs glycolysis and tumor growth. Cancer Res. 2016;76:3802-12. https://doi.org/10.1158/00085472. CAN-15-2498.

65. Lv L, Xu YP, Zhao D, Li FL, Wang W, Sasaki N, Jiang Y, Zhou X, Li TT, Guan $\mathrm{KL}$, Lei QY, Xiong Y. Mitogenic and oncogenic stimulation of K433 acetylation promotes PKM2 protein kinase activity and nuclear localization. Mol Cell. 2013;52:340-52. https://doi.org/10.1016/j.molcel.2013.09.004.

66. Nakatsu D, Horiuchi Y, Kano F, Noguchi Y, Sugawara T, Takamoto I, Kubota N, Kadowaki T, Murata M. L-cysteine reversibly inhibits glucose-induced biphasic insulin secretion and ATP production by inactivating PKM2. Proc Natl Acad Sci U S A. 2015;112:E1067-76. https://doi.org/10.1073/pnas. 1417197112.

67. Lo AK, Dawson CW, Young LS, Ko CW, Hau PM, Lo KW. Activation of the FGFR1 signalling pathway by the Epstein-Barr virus-encoded LMP1 promotes aerobic glycolysis and transformation of human nasopharyngeal epithelial cells. J Pathol. 2015;237:238-48. https://doi.org/10.1002/path.4575.

68. lansante V, Choy PM, Fung SW, Liu Y, Chai JG, Dyson J, Del Rio A, D'Santos C, Williams R, Chokshi S, Anders RA, Bubici C, Papa S. PARP14 promotes the Warburg effect in hepatocellular carcinoma by inhibiting JNK1-dependent PKM2 phosphorylation and activation. Nat Commun. 2015;6:7882. https:// doi.org/10.1038/ncomms8882.

69. Presek $P$, Reinacher M, Eigenbrodt E. Pyruvate kinase type $M 2$ is phosphorylated at tyrosine residues in cells transformed by Rous sarcoma virus. FEBS Lett. 1988;242:194-8. https://doi.org/10.1016/00145793(88)81014-7.

70. Clower CV, Chatterjee D, Wang Z, Cantley LC, Vander Heiden MG, Krainer AR. The alternative splicing repressors hnRNP A1/A2 and PTB influence pyruvate kinase isoform expression and cell metabolism. Proc Natl Acad Sci U S A. 2010:107:1894-9. https://doi.org/10.1073/pnas.0914845107.

71. Panasyuk G, Espeillac C, Chauvin C, Pradelli LA, Horie Y, Suzuki A, Annicotte JS, Fajas L, Foretz M, Verdeguer F, Pontoglio M, Ferre P, Scoazec JY, et al. PPARgamma contributes to PKM2 and HK2 expression in fatty liver. Nat Commun. 2012;3:672. https://doi.org/10.1038/ncomms1667.

72. Li YH, Li XF, Liu JT, Wang H, Fan LL, Li J, Sun GP. PKM2, a potential target for regulating cancer. Gene. 2018;668:48-53. https://doi.org/10.1016/j.gene. 2018.05.038

73. Wong N, Ojo D, Yan J, Tang D. PKM2 contributes to cancer metabolism. Cancer Lett. 2015;356:184-91. https://doi.org/10.1016/j.canlet.2014.01.031

74. Wong CC, Au SL, Tse AP, Xu IM, Lai RK, Chiu DK, Wei LL, Fan DN, Tsang FH, Lo RC, Wong CM, Ng IO. Switching of pyruvate kinase isoform $L$ to $M 2$ promotes metabolic reprogramming in hepatocarcinogenesis. PLoS One. 2014;9:e115036. https://doi.org/10.1371/journal.pone.0115036.

75. Feng J, Wu L, Ji J, Chen K, Yu Q, Zhang J, Chen J, Mao Y, Wang F, Dai W, Xu $L$, Wu J, Guo C. PKM2 is the target of proanthocyanidin B2 during the inhibition of hepatocellular carcinoma. J Exp Clin Cancer Res. 2019;38:204. https://doi.org/10.1186/s13046-019-1194-z

76. Liu B, Jin J, Zhang Z, Zuo L, Jiang M, Xie C. Shikonin exerts antitumor activity by causing mitochondrial dysfunction in hepatocellular carcinoma through PKM2-AMPK-PGC1alpha signaling pathway. Biochem Cell Biol. 2019; 97:397-405. https://doi.org/10.1139/bcb-2018-0310.

77. Vander Heiden MG, Cantley LC, Thompson CB. Understanding the Warburg effect: the metabolic requirements of cell proliferation. Science. 2009;324: 1029-33. https://doi.org/10.1126/science.1160809.
78. Ganapathy-Kanniappan S. Molecular intricacies of aerobic glycolysis in cancer: current insights into the classic metabolic phenotype. Crit Rev Biochem Mol Biol. 2018;53:667-82. https://doi.org/10.1080/10409238.2018. 1556578.

79. Mazurek S. Pyruvate kinase type M2: a key regulator of the metabolic budget system in tumor cells. Int J Biochem Cell Biol. 2011;43:969-80. https://doi.org/10.1016/j.biocel.2010.02.005.

80. Serganova I, Cohen IJ, Vemuri K, Shindo M, Maeda M, Mane M, Moroz E, Khanin R, Satagopan J, Koutcher JA, Blasberg R. LDH-A regulates the tumor microenvironment via HIF-signaling and modulates the immune response. PLoS One. 2018;13:e0203965. https://doi.org/10.1371/journal.pone.0203965.

81. Li Y, Lu Z, Liang Z, Ji D, Zhang P, Liu Q, Zheng X, Yao Y. Metastasisassociated in colon cancer-1 is associated with poor prognosis in hepatocellular carcinoma, partly by promoting proliferation through enhanced glucose metabolism. Mol Med Rep. 2015;12:426-34. https://doi. org/10.3892/mmr.2015.3416.

82. Gatenby RA, Gillies RJ. Why do cancers have high aerobic glycolysis? Nat Rev Cancer. 2004;4:891-9. https://doi.org/10.1038/nrc1478.

83. Williams AC, Collard TJ, Paraskeva C. An acidic environment leads to p53 dependent induction of apoptosis in human adenoma and carcinoma cell lines: implications for clonal selection during colorectal carcinogenesis. Oncogene. 1999;18:3199-204. https://doi.org/10.1038/sj.onc.1202660.

84. Lardner A. The effects of extracellular $\mathrm{pH}$ on immune function. J Leukoc Biol. 2001;69:522-30

85. Shang F, Liu M, Li B, Zhang X, Sheng Y, Liu S, Han J, Li H, Xiu R. The antiangiogenic effect of dexamethasone in a murine hepatocellular carcinoma model by augmentation of gluconeogenesis pathway in malignant cells. Cancer Chemother Pharmacol. 2016;77:1087-96. https://doi.org/10.1007/ s00280-016-3030-X.

86. Liu Y, Bi T, Shen G, Li Z, Wu G, Wang Z, Qian L, Gao Q. Lupeol induces apoptosis and inhibits invasion in gallbladder carcinoma GBC-SD cells by suppression of EGFR/MMP-9 signaling pathway. Cytotechnology. 2016;68: 123-33. https://doi.org/10.1007/s10616-014-9763-7.

87. Shi Q, Le X, Wang B, Abbruzzese JL, Xiong Q, He Y, Xie K. Regulation of vascular endothelial growth factor expression by acidosis in human cancer cells. Oncogene. 2001;20:3751-6. https://doi.org/10.1038/sj.onc.1204500.

88. Jung SY, Song HS, Park SY, Chung SH, Kim YJ. Pyruvate promotes tumor angiogenesis through HIF-1-dependent PAI-1 expression. Int J Oncol. 2011; 38:571-6. https://doi.org/10.3892/ijo.2010.859.

89. Graziano F, Ruzzo A, Giacomini E, Ricciardi T, Aprile G, Loupakis F, Lorenzini P, Ongaro E, Zoratto F, Catalano V, Sarti D, Rulli E, Cremolini C, et al. Glycolysis gene expression analysis and selective metabolic advantage in the clinical progression of colorectal cancer. Pharmacogenomics J. 2017;17: 258-64. https://doi.org/10.1038/tpj.2016.13.

90. Feng J, Dai W, Mao Y, Wu L, Li J, Chen K, Yu Q, Kong R, Li S, Zhang J, Ji J, Wu J, Mo W, et al. Simvastatin re-sensitizes hepatocellular carcinoma cells to sorafenib by inhibiting HIF-1alpha/PPAR-gamma/PKM2-mediated glycolysis. J Exp Clin Cancer Res. 2020;39:24. https://doi.org/10.1186/s13046-020-1528-x.

91. Wang L, Yang Q, Peng S, Liu X. The combination of the glycolysis inhibitor 2-DG and sorafenib can be effective against sorafenib-tolerant persister cancer cells. Onco Targets Ther. 2019;12:5359-73. https://doi.org/10.2147/ OTT.S212465.

92. Pastorino JG, Shulga N, Hoek JB. Mitochondrial binding of hexokinase ॥ inhibits Bax-induced cytochrome c release and apoptosis. J Biol Chem. 2002;277:7610-8. https://doi.org/10.1074/jbc.M109950200.

93. Min JW, Kim Kl, Kim HA, Kim EK, Noh WC, Jeon HB, Cho DH, Oh JS, Park IC, Hwang SG, Kim JS. INPP4B-mediated tumor resistance is associated with modulation of glucose metabolism via hexokinase 2 regulation in laryngeal cancer cells. Biochem Biophys Res Commun. 2013:440:137-42. https://doi. org/10.1016/j.bbrc.2013.09.041.

94. Shen YC, Ou DL, Hsu C, Lin KL, Chang CY, Lin CY, Liu SH, Cheng AL. Activating oxidative phosphorylation by a pyruvate dehydrogenase kinase inhibitor overcomes sorafenib resistance of hepatocellular carcinoma. $\mathrm{Br} \mathrm{J}$ Cancer. 2013;108:72-81. https://doi.org/10.1038/bjc.2012.559.

95. Morita M, Sato T, Nomura M, Sakamoto Y, Inoue Y, Tanaka R, Ito S, Kurosawa K, Yamaguchi K, Sugiura Y, Takizaki H, Yamashita Y, Katakura R, et al. PKM1 confers metabolic advantages and promotes cell-autonomous tumor cell growth. Cancer Cell. 2018:33:355-67 e7. https://doi.org/10.1016/j.ccell.2018.02.004.

96. Comerford KM, Wallace TJ, Karhausen J, Louis NA, Montalto MC, Colgan SP. Hypoxia-inducible factor-1-dependent regulation of the multidrug resistance (MDR1) gene. Cancer Res. 2002;62:3387-94. 
97. Fischer K, Hoffmann P, Voelkl S, Meidenbauer N, Ammer J, Edinger M, Gottfried E, Schwarz S, Rothe G, Hoves S, Renner K, Timischl B, Mackensen $A$, et al. Inhibitory effect of tumor cell-derived lactic acid on human T cells. Blood. 2007;109:3812-9. https://doi.org/10.1182/blood-2006-07-035972.

98. Egan DF, Shackelford DB, Mihaylova MM, Gelino S, Kohnz RA, Mair W, Vasquez DS, Joshi A, Gwinn DM, Taylor R, Asara JM, Fitzpatrick J, Dillin A, et al. Phosphorylation of ULK1 (hATG1) by AMP-activated protein kinase connects energy sensing to mitophagy. Science. 2011;331:456-61. https:// doi.org/10.1126/science.1196371.

99. Hawley SA, Fullerton MD, Ross FA, Schertzer JD, Chevtzoff C, Walker KJ, Peggie MW, Zibrova D, Green KA, Mustard KJ, Kemp BE, Sakamoto K, Steinberg GR, et al. The ancient drug salicylate directly activates AMPactivated protein kinase. Science. 2012;336:918-22. https://doi.org/10.1126/ science.1215327

100. Hurley RL, Barre LK, Wood SD, Anderson KA, Kemp BE, Means AR, Witters LA Regulation of AMP-activated protein kinase by multisite phosphorylation in response to agents that elevate cellular CAMP. J Biol Chem. 2006;281:3666272. https://doi.org/10.1074/jbc.M606676200.

101. Dagon Y, Hur E, Zheng B, Wellenstein K, Cantley LC, Kahn BB. p70S6 kinase phosphorylates AMPK on serine 491 to mediate leptin's effect on food intake. Cell Metab. 2012;16:104-12. https://doi.org/10.1016/j.cmet.2012.05.010.

102. Fang G, Zhang P, Liu J, Zhang X, Zhu X, Li R, Wang H. Inhibition of GSK3beta activity suppresses HCC malignant phenotype by inhibiting glycolysis via activating AMPK/mTOR signaling. Cancer Lett. 2019;463:11-26. https:// doi.org/10.1016/j.canlet.2019.08.003.

103. Cheng J, Zhang T, Ji H, Tao K, Guo J, Wei W. Functional characterization of AMP-activated protein kinase signaling in tumorigenesis. Biochim Biophys Acta. 1866;2016:232-51. https://doi.org/10.1016/j.bbcan.2016.09.006.

104. Faubert B, Boily G, Izreig S, Griss T, Samborska B, Dong Z, Dupuy F, Chambers C, Fuerth BJ, Viollet B, Mamer OA, Avizonis D, DeBerardinis RJ, et al. AMPK is a negative regulator of the Warburg effect and suppresses tumor growth in vivo. Cell Metab. 2013;17:113-24. https://doi.org/10.1016/j. cmet.2012.12.001.

105. Yoshida GJ. Metabolic reprogramming: the emerging concept and associated therapeutic strategies. J Exp Clin Cancer Res. 2015;34:111. https:// doi.org/10.1186/s13046-015-0221-y.

106. Ren Y, Shen HM. Critical role of AMPK in redox regulation under glucose starvation. Redox Biol. 2019;25:101154. https://doi.org/10.1016/j.redox.2019. 101154

107. Gao L, LV G, Li R, Liu WT, Zong C, Ye F, Li XY, Yang X, Jiang JH, Hou XJ, Jing YY, Han ZP, Wei LX. Glycochenodeoxycholate promotes hepatocellular carcinoma invasion and migration by AMPK/mTOR dependent autophagy activation. Cancer Lett. 2019;454:215-23. https://doi.org/10.1016/j.canlet. 2019.04.009

108. Hardie DG. AMPK: a target for drugs and natural products with effects on both diabetes and cancer. Diabetes. 2013;62:2164-72. https://doi.org/10. 2337/db13-0368

109. Hardie DG, Ross FA, Hawley SA. AMPK: a nutrient and energy sensor that maintains energy homeostasis. Nat Rev Mol Cell Biol. 2012;13:251-62. https://doi.org/10.1038/nrm3311.

110. Domenech E, Maestre C, Esteban-Martinez L, Partida D, Pascual R, Fernandez-Miranda G, Seco E, Campos-Olivas R, Perez M, Megias D, Allen K, Lopez M, Saha AK, et al. AMPK and PFKFB3 mediate glycolysis and survival in response to mitophagy during mitotic arrest. Nat Cell Biol. 2015;17:130416. https://doi.org/10.1038/ncb3231.

111. Yoshida GJ. Therapeutic strategies of drug repositioning targeting autophagy to induce cancer cell death: from pathophysiology to treatment. J Hematol Oncol. 2017;10:67. https://doi.org/10.1186/s13045-017-0436-9.

112. Huang F, Wang BR, Wang YG. Role of autophagy in tumorigenesis, metastasis, targeted therapy and drug resistance of hepatocellular carcinoma. World J Gastroenterol. 2018;24:4643-51. https://doi.org/10.3748/ wjg.v24.i41.4643.

113. Lee YJ, Jang BK. The role of autophagy in hepatocellular carcinoma. Int J Mol Sci. 2015;16:26629-43. https://doi.org/10.3390/ijms161125984.

114. Qu X, Yu J, Bhagat G, Furuya N, Hibshoosh H, Troxel A, Rosen J, Eskelinen EL, Mizushima N, Ohsumi Y, Cattoretti G, Levine B. Promotion of tumorigenesis by heterozygous disruption of the beclin 1 autophagy gene. J Clin Invest. 2003;112:1809-20. https://doi.org/10.1172/JCI20039.

115. Kim J, Kundu M, Viollet B, Guan KL. AMPK and mTOR regulate autophagy through direct phosphorylation of Ulk1. Nat Cell Biol. 2011;13:132-41. https://doi.org/10.1038/ncb2152.
116. Yan Y, Xu Z, Dai S, Qian L, Sun L, Gong Z. Targeting autophagy to sensitive glioma to temozolomide treatment. J Exp Clin Cancer Res. 2016;35:23. https://doi.org/10.1186/s13046-016-0303-5.

117. Moldogazieva NT, Mokhosoev IM, Terentiev AA. Metabolic Heterogeneity of Cancer Cells: An Interplay between HIF-1, GLUTs, and AMPK. Cancers (Basel). 2020;12. https://doi.org/10.3390/cancers12040862.

118. Fruman DA, Rommel C. PI3K and cancer: lessons, challenges and opportunities. Nat Rev Drug Discov. 2014;13:140-56. https:/doi.org/10.1038/nrd4204.

119. Nicholson KM, Anderson NG. The protein kinase B/Akt signalling pathway in human malignancy. Cell Signal. 2002;14:381-95. https://doi.org/10.1016/ s0898-6568(01)00271-6.

120. Guerrero-Zotano A, Mayer IA, Arteaga CL. PI3K/AKT/mTOR: role in breast cancer progression, drug resistance, and treatment. Cancer Metastasis Rev. 2016;35:515-24. https://doi.org/10.1007/s10555-016-9637-x.

121. Fu X, Liu M, Qu S, Ma J, Zhang Y, Shi T, Wen H, Yang Y, Wang S, Wang J, Nan $K$, Yao $Y$, Tian T. Exosomal microRNA-32-5p induces multidrug resistance in hepatocellular carcinoma via the PI3K/Akt pathway. J Exp Clin Cancer Res. 2018;37:52. https://doi.org/10.1186/s13046-018-0677-7.

122. Zhu YJ, Zheng B, Wang HY, Chen L. New knowledge of the mechanisms of sorafenib resistance in liver cancer. Acta Pharmacol Sin. 2017;38:614-22. https://doi.org/10.1038/aps.2017.5.

123. Zhang H, Wang Q, Liu J, Cao H. Inhibition of the PI3K/Akt signaling pathway reverses sorafenib-derived chemo-resistance in hepatocellular carcinoma. Oncol Lett. 2018;15:9377-84. https://doi.org/10.3892/ol.2018.8536.

124. Melstrom LG, Salabat MR, Ding XZ, Milam BM, Strouch M, Pelling JC, Bentrem DJ. Apigenin inhibits the GLUT-1 glucose transporter and the phosphoinositide 3-kinase/Akt pathway in human pancreatic cancer cells. Pancreas. 2008;37:426-31. https://doi.org/10.1097/MPA.0b013e3181735ccb.

125. Garrido P, Moran J, Alonso A, Gonzalez S, Gonzalez C. 17beta-estradiol activates glucose uptake via GLUT4 translocation and PI3K/Akt signaling pathway in MCF-7 cells. Endocrinology. 2013;154:1979-89. https://doi.org/ 10.1210/en.2012-1558

126. Samih N, Hovsepian S, Aouani A, Lombardo D, Fayet G. Glut-1 translocation in FRTL-5 thyroid cells: role of phosphatidylinositol 3-kinase and N-glycosylation. Endocrinology. 2000;141:4146-55. https://doi.org/10.1210/endo.141.11.7793.

127. Elstrom RL, Bauer DE, Buzzai M, Karnauskas R, Harris MH, Plas DR, Zhuang $H_{\text {, }}$ Cinalli RM, Alavi A, Rudin CM, Thompson CB. Akt stimulates aerobic glycolysis in cancer cells. Cancer Res. 2004:64:3892-9. https://doi.org/10. 1158/0008-5472.CAN-03-2904.

128. Robey RB, Hay N. Mitochondrial hexokinases, novel mediators of the antiapoptotic effects of growth factors and Akt. Oncogene. 2006;25:468396. https://doi.org/10.1038/sj.onc. 1209595.

129. Grahame HD. AMP-activated protein kinase: a key regulator of energy balance with many roles in human disease. J Intern Med. 2014;276:543-59. https://doi.org/10.1111/joim.12268.

130. Semenza GL, Wang GL. A nuclear factor induced by hypoxia via de novo protein synthesis binds to the human erythropoietin gene enhancer at a site required for transcriptional activation. Mol Cell Biol. 1992;12:5447-54. https://doi.org/10.1128/mcb.12.12.5447.

131. Semenza GL. Targeting HIF-1 for cancer therapy. Nat Rev Cancer. 2003;3: 721-32. https://doi.org/10.1038/nrc1187.

132. Huang LE. Carrot and stick: HIF-alpha engages c-Myc in hypoxic adaptation. Cell Death Differ. 2008;15:672-7. https://doi.org/10.1038/sj.cdd.4402302.

133. Yao J, Man S, Dong H, Yang L, Ma L, Gao W. Combinatorial treatment of Rhizoma Paridis saponins and sorafenib overcomes the intolerance of sorafenib. J Steroid Biochem Mol Biol. 2018;183:159-66. https://doi.org/10. 1016/j.jsbmb.2018.06.010.

134. Marin-Hernandez A, Gallardo-Perez JC, Ralph SJ, Rodriguez-Enriquez S, Moreno-Sanchez R. HIF-1alpha modulates energy metabolism in cancer cells by inducing over-expression of specific glycolytic isoforms. Mini Rev Med Chem. 2009;9:1084-101. https://doi.org/10.2174/138955709788922610.

135. Kim JW, Tchernyshyov I, Semenza GL, Dang CV. HIF-1-mediated expression of pyruvate dehydrogenase kinase: a metabolic switch required for cellular adaptation to hypoxia. Cell Metab. 2006;3:177-85. https://doi.org/10.1016/j. cmet.2006.02.002.

136. DeBerardinis RJ, Lum JJ, Hatzivassiliou G, Thompson CB. The biology of cancer: metabolic reprogramming fuels cell growth and proliferation. Cell Metab. 2008;7:11-20. https://doi.org/10.1016/j.cmet.2007.10.002.

137. Yoshida GJ. Emerging roles of Myc in stem cell biology and novel tumor therapies. J Exp Clin Cancer Res. 2018;37:173. https://doi.org/10.1186/ s13046-018-0835-y. 
138. Lin CP, Liu CR, Lee CN, Chan TS, Liu HE. Targeting C-Myc as a novel approach for hepatocellular carcinoma. World J Hepatol. 2010;2:16-20 https://doi.org/10.4254/wjh.v2.11.16.

139. Mendez-Lucas A, Li X, Hu J, Che L, Song X, Jia J, Wang J, Xie C, Driscoll PC, Tschaharganeh DF, Calvisi DF, Yuneva M, Chen X. Glucose catabolism in liver tumors induced by c-MYC can be sustained by various PKM1/PKM2 ratios and pyruvate kinase activities. Cancer Res. 2017;77:4355-64. https:// doi.org/10.1158/0008-5472.CAN-17-0498.

140. Gruning NM, Lehrach H, Ralser M. Regulatory crosstalk of the metabolic network. Trends Biochem Sci. 2010;35:220-7. https://doi.org/10.1016/j.tibs. 2009.12.001.

141. Dang CV, Kim JW, Gao P, Yustein J. The interplay between MYC and HIF in cancer. Nat Rev Cancer. 2008:8:51-6. https://doi.org/10.1038/nrc2274.

142. Yang W, Zheng Y, Xia Y, Ji H, Chen X, Guo F, Lyssiotis CA, Aldape K, Cantley LC, Lu Z. ERK1/2-dependent phosphorylation and nuclear translocation of PKM2 promotes the Warburg effect. Nat Cell Biol. 2012;14:1295-304. https:// doi.org/10.1038/ncb2629.

143. Kim JW, Gao P, Liu YC, Semenza GL, Dang CV. Hypoxia-inducible factor 1 and dysregulated c-Myc cooperatively induce vascular endothelial growth factor and metabolic switches hexokinase 2 and pyruvate dehydrogenase kinase 1. Mol Cell Biol. 2007;27:7381-93. https://doi.org/10.1128/MCB.00440-07.

144. Dang CV, Le A, Gao P. MYC-induced cancer cell energy metabolism and therapeutic opportunities. Clin Cancer Res. 2009;15:6479-83. https://doi.org/ 10.1158/1078-0432.CCR-09-0889.

145. Lin CP, Liu JD, Chow JM, Liu CR, Liu HE. Small-molecule c-Myc inhibitor, 10058-F4, inhibits proliferation, downregulates human telomerase reverse transcriptase and enhances chemosensitivity in human hepatocellular carcinoma cells. Anti-Cancer Drugs. 2007;18:161-70. https://doi.org/10.1097/ CAD.0b013e3280109424

146. Yao YX, Xu BH, Zhang Y. CX-3543 promotes cell apoptosis through Downregulation of CCAT1 in Colon Cancer cells. Biomed Res Int. 2018;2018: 9701957. https://doi.org/10.1155/2018/9701957.

147. Esteller M. Non-coding RNAs in human disease. Nat Rev Genet. 2011;12: 861-74. https://doi.org/10.1038/nrg3074.

148. Liu W, Kang L, Han J, Wang Y, Shen C, Yan Z, Tai Y, Zhao C. miR-342-3p suppresses hepatocellular carcinoma proliferation through inhibition of IGF1R-mediated Warburg effect. Onco Targets Ther. 2018;11:1643-53. https:// doi.org/10.2147/OTT.S161586.

149. Ren L, Yao Y, Wang Y, Wang S. MiR-505 suppressed the growth of hepatocellular carcinoma cells via targeting IGF-1R. Biosci Rep. 2019;39. https://doi.org/10.1042/BSR20182442.

150. Hu Y, Yang Z, Bao D, Ni JS, Lou J. miR-455-5p suppresses hepatocellular carcinoma cell growth and invasion via IGF-1R/AKT/GLUT1 pathway by targeting IGF-1R. Pathol Res Pract. 2019;215:152674. https://doi.org/10.1016/j. prp.2019.152674

151. Wei S, Fan Q, Yang L, Zhang X, Ma Y, Zong Z, Hua X, Su D, Sun H, Li H, Liu Z. Promotion of glycolysis by HOTAIR through GLUT1 upregulation via mTOR signaling. Oncol Rep. 2017;38:1902-8. https://doi.org/10.3892/or. 2017.5840.

152. Hua S, Lei L, Deng L, Weng X, Liu C, Qi X, Wang S, Zhang D, Zou X, Cao C, Liu L, Wu D. miR-139-5p inhibits aerobic glycolysis, cell proliferation, migration, and invasion in hepatocellular carcinoma via a reciprocal regulatory interaction with ETS1. Oncogene. 2018;37:1624-36. https://doi. org/10.1038/s41388-017-0057-3.

153. Kim HR, Roe JS, Lee JE, Cho EJ, Youn HD. p53 regulates glucose metabolism by miR-34a. Biochem Biophys Res Commun. 2013;437:225-31. https://doi. org/10.1016/.jbbrc.2013.06.043.

154. Jiang JX, Gao S, Pan YZ, Yu C, Sun CY. Overexpression of microRNA-125b sensitizes human hepatocellular carcinoma cells to 5 -fluorouracil through inhibition of glycolysis by targeting hexokinase II. Mol Med Rep. 2014;10: 995-1002. https://doi.org/10.3892/mmr.2014.2271.

155. Li W, Hao J, Zhang L, Cheng Z, Deng X, Shu G. Astragalin reduces hexokinase 2 through increasing miR-125b to inhibit the proliferation of hepatocellular carcinoma cells in vitro and in vivo. J Agric Food Chem. 2017;65:5961-72. https://doi.org/10.1021/acs.jafc.7b02120.

156. Lin YH, Wu MH, Huang YH, Yeh CT, Cheng ML, Chi HC, Tsai CY, Chung IH, Chen CY, Lin KH. Taurine up-regulated gene 1 functions as a master regulator to coordinate glycolysis and metastasis in hepatocellular carcinoma. Hepatology. 2018;67:188-203. https://doi.org/10.1002/hep.29462.

157. Guo W, Qiu Z, Wang Z, Wang Q, Tan N, Chen T, Chen Z, Huang S, Gu J, Li J, Yao M, Zhao Y, He X. MiR-199a-5p is negatively associated with malignancies and regulates glycolysis and lactate production by targeting hexokinase 2 in liver cancer. Hepatology. 2015;62:1132-44. https://doi.org/ 10.1002/hep.27929.

158. Zhang LF, Lou JT, Lu MH, Gao C, Zhao S, Li B, Liang S, Li Y, Li D, Liu MF. Suppression of miR-199a maturation by HuR is crucial for hypoxia-induced glycolytic switch in hepatocellular carcinoma. EMBO J. 2015;34:2671-85. https://doi.org/10.15252/embj.201591803.

159. Xu F, Yan JJ, Gan Y, Chang Y, Wang HL, He XX, Zhao Q. miR-885-5p negatively regulates Warburg effect by silencing hexokinase 2 in liver Cancer. Mol Ther Nucleic Acids. 2019;18:308-19. https://doi.org/10.1016/j. omtn.2019.09.002.

160. Park YY, Kim SB, Han HD, Sohn BH, Kim JH, Liang J, Lu Y, Rodriguez-Aguayo C, Lopez-Berestein G, Mills GB, Sood AK, Lee JS. Tat-activating regulatory DNA-binding protein regulates glycolysis in hepatocellular carcinoma by regulating the platelet isoform of phosphofructokinase through microRNA 520. Hepatology. 2013;58:182-91. https://doi.org/10.1002/hep.26310.

161. Xu Q, Zhang M, Tu J, Pang L, Cai W, Liu X. MicroRNA-122 affects cell aggressiveness and apoptosis by targeting PKM2 in human hepatocellular carcinoma. Oncol Rep. 2015;34:2054-64. https://doi.org/ 10.3892/or.2015.4175

162. Li Q, Pan X, Zhu D, Deng Z, Jiang R, Wang X. Circular RNA MAT2B promotes glycolysis and malignancy of hepatocellular carcinoma through the miR338-3p/PKM2 Axis under hypoxic stress. Hepatology. 2019;70:1298-316. https://doi.org/10.1002/hep.30671.

163. Zheng YL, Li L, Jia YX, Zhang BZ, Li JC, Zhu YH, Li MQ, He JZ, Zeng TT, Ban XJ, Yuan YF, Li Y, Guan XY. LINC01554-mediated glucose metabolism reprogramming suppresses Tumorigenicity in hepatocellular carcinoma via Downregulating PKM2 expression and inhibiting Akt/mTOR signaling pathway. Theranostics. 2019;9:796-810. https://doi.org/10.7150/thno.28992.

164. Xu Q, Dou C, Liu X, Yang L, Ni C, Wang J, Guo Y, Yang W, Tong X, Huang D. Oviductus ranae protein hydrolysate (ORPH) inhibits the growth, metastasis and glycolysis of HCC by targeting miR-491-5p/PKM2 axis. Biomed Pharmacother. 2018;107:1692-704. https://doi.org/10.1016/j. biopha.2018.07.071.

165. Zhang M, Zhang H, Hong H, Zhang Z. MiR-374b re-sensitizes hepatocellular carcinoma cells to sorafenib therapy by antagonizing PKM2-mediated glycolysis pathway. Am J Cancer Res. 2019;9:765-78.

166. Hua S, Liu C, Liu L, Wu D. miR-142-3p inhibits aerobic glycolysis and cell proliferation in hepatocellular carcinoma via targeting LDHA. Biochem Biophys Res Commun. 2018;496:947-54. https://doi.org/10. 1016/j.bbrc.2018.01.112.

167. Li X, Lu P, Li B, Yang R, Chu Y, Zhang Z, Wan H, Niu C, Wang C, Luo K. Sensitization of hepatocellular carcinoma cells to irradiation by miR34a through targeting lactate dehydrogenaseA. Mol Med Rep. 2016;13:3661-7. https://doi.org/10.3892/mmr.2016.4974.

168. Zhang HF, Wang YC, Han YD. MicroRNA34a inhibits liver cancer cell growth by reprogramming glucose metabolism. Mol Med Rep. 2018;17:4483-9. https://doi.org/10.3892/mmr.2018.8399.

169. Li B, He L, Zuo D, He W, Wang Y, Zhang Y, Liu W, Yuan Y. Mutual regulation of MiR-199a-5p and HIF-1alpha modulates the Warburg effect in hepatocellular carcinoma. J Cancer. 2017:8:940-9. https://doi.org/10.7150//ca.17496.

170. Chen Z, Zuo X, Zhang Y, Han G, Zhang L, Wu J, Wang X. MiR-3662 suppresses hepatocellular carcinoma growth through inhibition of HIF1alpha-mediated Warburg effect. Cell Death Dis. 2018;9:549. https://doi.org/ 10.1038/s41419-018-0616-8.

171. Tang H, Li RP, Liang P, Zhou YL, Wang GW. miR-125a inhibits the migration and invasion of liver cancer cells via suppression of the PI3K/AKT/mTOR signaling pathway. Oncol Lett. 2015;10:681-6. https://doi.org/10.3892/ol. 2015.3264.

172. Fang Y, Xue JL, Shen Q, Chen J, Tian L. MicroRNA-7 inhibits tumor growth and metastasis by targeting the phosphoinositide 3-kinase/Akt pathway in hepatocellular carcinoma. Hepatology. 2012;55:1852-62. https://doi.org/10. 1002/hep.25576.

173. Gao P, Tchernyshyov I, Chang TC, Lee YS, Kita K, Ochi T, Zeller KI, De Marzo AM, Van Eyk JE, Mendell JT, Dang CV. C-Myc suppression of miR-23a/b enhances mitochondrial glutaminase expression and glutamine metabolism. Nature. 2009;458:762-5. https://doi.org/10.1038/nature07823.

174. Han H, Li W, Shen H, Zhang J, Zhu Y, Li Y. microRNA-129-5p, a c-Myc negative target, affects hepatocellular carcinoma progression by blocking the Warburg effect. J Mol Cell Biol. 2016;8:400-10. https://doi.org/10.1093/ jmcb/mjw010 
175. Ren W, Wu S, Wu Y, Liu T, Zhao X, Li Y. MicroRNA-196a/-196b regulate the progression of hepatocellular carcinoma through modulating the JAKVSTAT pathway via targeting SOCS2. Cell Death Dis. 2019;10:333. https://doi.org/10. 1038/s41419-019-1530-4.

176. Li X, Zhao Q, Qi J, Wang W, Zhang D, Li Z, Qin C. IncRNA Ftx promotes aerobic glycolysis and tumor progression through the PPARgamma pathway in hepatocellular carcinoma. Int J Oncol. 2018;53:551-66. https:// doi.org/10.3892/ijo.2018.4418.

177. Malakar P, Stein I, Saragovi A, Winkler R, Stern-Ginossar N, Berger M, Pikarsky E, Karni R. Long noncoding RNA MALAT1 regulates Cancer glucose metabolism by enhancing mTOR-mediated translation of TCF7L2. Cancer Res. 2019;79:2480-93. https://doi.org/10.1158/0008-5472.CAN-18-1432.

178. Reyes RK, Motiwala T, Jacob ST. Regulation of glucose metabolism in hepatocarcinogenesis by microRNAs. Gene Expr. 2014;16:85-92. https://doi. org/10.3727/105221614X13919976902093.

179. Wang Z, Kang F, Gao Y, Liu Y, Xu X, Ma X, Ma W, Yang W, Wang J. Metformin promotes 2-Deoxy-2-[(18)F]Fluoro-D-glucose uptake in hepatocellular carcinoma cells through FoxO1-mediated Downregulation of Glucose-6-phosphatase. Mol Imaging Biol. 2018;20:388-97. https://doi.org/10.1007/s11307-017-1150-2.

180. Tomizawa M, Shinozaki F, Motoyoshi Y, Sugiyama T, Yamamoto S, Ishige N. 2-Deoxyglucose and sorafenib synergistically suppress the proliferation and motility of hepatocellular carcinoma cells. Oncol Lett. 2017;13:800-4. https:// doi.org/10.3892/ol.2016.5510.

181. Takemura A, Che XF, Tabuchi T, Moriya S, Miyazawa K, Tomoda A. Enhancement of cytotoxic and pro-apoptotic effects of 2aminophenoxazine-3-one on the rat hepatocellular carcinoma cell line dRLh-84, the human hepatocellular carcinoma cell line HepG2, and the rat normal hepatocellular cell line RLN-10 in combination with 2-deoxy-Dglucose. Oncol Rep. 2012;27:347-55. https://doi.org/10.3892/or.2011.1531.

182. Geschwind JF, Georgiades CS, Ko YH, Pedersen PL. Recently elucidated energy catabolism pathways provide opportunities for novel treatments in hepatocellular carcinoma. Expert Rev Anticancer Ther. 2004;4:449-57. https://doi.org/10.1586/14737140.4.3.449.

183. Telang S, Clem BF, Klarer AC, Clem AL, Trent JO, Bucala R, Chesney J. Small molecule inhibition of 6-phosphofructo-2-kinase suppresses t cell activation. J Transl Med. 2012;10:95. https://doi.org/10.1186/1479-5876-10-95.

184. Wang Y, Hao F, Nan Y, Qu L, Na W, Jia C, Chen X. PKM2 inhibitor Shikonin overcomes the Cisplatin resistance in bladder Cancer by inducing Necroptosis. Int J Biol Sci. 2018;14:1883-91. https://doi.org/10.7150/ijbs.27854.

185. Szokoloczi O, Schwab R, Petak I, Orfi L, Pap A, Eberle AN, Szuts T, Keril G. TT232, a novel signal transduction inhibitory compound in the therapy of cancer and inflammatory diseases. J Recept Signal Transduct Res. 2005;25: 217-35. https://doi.org/10.1080/10799890500464621.

186. Liu T, Li S, Wu L, Yu Q, Li J, Feng J, Zhang J, Chen J, Zhou Y, Ji J, Chen K, Mao $Y$, Wang $F$, et al. Experimental study of hepatocellular carcinoma treatment by Shikonin through regulating PKM2. J Hepatocell Carcinoma. 2020;7:19-31. https://doi.org/10.2147/JHC.S237614

187. Dumenci OE, Abellona UM, Khan SA, Holmes E, Taylor-Robinson SD. Exploring metabolic consequences of CPS1 and CAD Dysregulation in hepatocellular carcinoma by network reconstruction. J Hepatocell Carcinoma. 2020;7:1-9. https://doi.org/10.2147/JHC.S239039.

188. Li J, Guo C, Wu J. 15-Deoxy--(12,14)-prostaglandin J2 (15d-PGJ2), an endogenous ligand of PPAR-gamma: function and mechanism. PPAR Res. 2019;2019:7242030. https://doi.org/10.1155/2019/7242030.

189. Wu L, Li J, Liu T, Li S, Feng J, Yu Q, Zhang J, Chen J, Zhou Y, Ji J, Chen K, Mao Y, Wang F, et al. Quercetin shows anti-tumor effect in hepatocellular carcinoma LM3 cells by abrogating JAK2/STAT3 signaling pathway. Cancer Med. 2019;8:4806-20. https://doi.org/10.1002/cam4.2388.

190. Wang W, Wu L, Li J, Ji J, Chen K, Yu Q, Li S, Feng J, Liu T, Zhang J, Chen J, Zhou Y, Mao Y, et al. Alleviation of hepatic ischemia reperfusion injury by Oleanolic acid pretreating via reducing HMGB1 release and inhibiting apoptosis and autophagy. Mediat Inflamm. 2019;2019:3240713. https://doi. org/10.1155/2019/3240713.

191. Kudo M, Finn RS, Qin S, Han KH, Ikeda K, Piscaglia F, Baron A, Park JW, Han G, Jassem J, Blanc JF, Vogel A, Komov D, et al. Lenvatinib versus sorafenib in first-line treatment of patients with unresectable hepatocellular carcinoma: a randomised phase 3 non-inferiority trial. Lancet. 2018;391:1163-73. https:// doi.org/10.1016/S0140-6736(18)30207-1.

192. Faivre S, Rimassa L, Finn RS. Molecular therapies for HCC: looking outside the box. J Hepatol. 2020;72:342-52. https://doi.org/10.1016/j. jhep.2019.09.010.
193. Ikeda M, Morizane C, Ueno M, Okusaka T, Ishii H, Furuse J. Chemotherapy for hepatocellular carcinoma: current status and future perspectives. Jpn J Clin Oncol. 2018;48:103-14. https://doi.org/10.1093/jjco/hyx180.

194. Thomas MB, Garrett-Mayer E, Anis M, Anderton K, Bentz T, Edwards A, Brisendine A, Weiss G, Siegel AB, Bendell J, Baron A, Duddalwar V, ElKhoueiry A. A randomized phase II open-label multi-institution study of the combination of Bevacizumab and Erlotinib compared to Sorafenib in the first-line treatment of patients with advanced hepatocellular carcinoma. Oncology. 2018;94:329-39. https://doi.org/10.1159/000485384.

195. von Felden J. New systemic agents for hepatocellular carcinoma: an update 2020. Curr Opin Gastroenterol. 2020;36:177-83. https://doi.org/10.1097/MOG. 0000000000000626.

196. Itoh S, Yoshizumi T, Yugawa K, Imai D, Yoshiya S, Takeishi K, Toshima T, Harada N, Ikegami T, Soejima Y, Kohashi K, Oda Y, Mori M. Impact of immune response on outcomes in hepatocellular carcinoma: association with vascular formation. Hepatology. 2020. https://doi.org/10.1002/hep. 31206.

197. Kudo M. Scientific Rationale for Combined Immunotherapy with PD-1/PDL1 Antibodies and VEGF Inhibitors in Advanced Hepatocellular Carcinoma. Cancers (Basel). 2020;12. https://doi.org/10.3390/cancers12051089.

198. Hack SP, Spahn J, Chen M, Cheng AL, Kaseb A, Kudo M, Lee HC, Yopp A, Chow P, Qin S. IMbrave 050: a phase III trial of atezolizumab plus bevacizumab in high-risk hepatocellular carcinoma after curative resection or ablation. Future Oncol. 2020. https://doi.org/10.2217/fon-2020-0162.

199. Finn RS, Qin S, Ikeda M, Galle PR, Ducreux M, Kim TY, Kudo M, Breder V, Merle P, Kaseb AO, Li D, Verret W, Xu DZ, et al. Atezolizumab plus Bevacizumab in Unresectable Hepatocellular Carcinoma. N Engl J Med. 2020;382:1894-905. https://doi.org/10.1056/NEJMoa1915745.

200. Zhang H, Li XX, Yang Y, Zhang Y, Wang HY, Zheng XFS. Significance and mechanism of androgen receptor overexpression and androgen receptor/ mechanistic target of rapamycin cross-talk in hepatocellular carcinoma. Hepatology. 2018;67:2271-86. https://doi.org/10.1002/hep.29715.

201. Wang SH, Yeh SH, Lin WH, Wang HY, Chen DS, Chen PJ. Identification of androgen response elements in the enhancer I of hepatitis B virus: a mechanism for sex disparity in chronic hepatitis B. Hepatology. 2009;50: 1392-402. https://doi.org/10.1002/hep.23163.

202. Ma WL, Hsu CL, Wu MH, Wu CT, Wu CC, Lai JJ, Jou YS, Chen CW, Yeh S, Chang C. Androgen receptor is a new potential therapeutic target for the treatment of hepatocellular carcinoma. Gastroenterology. 2008;135:947-55, 55 e1-5. https://doi.org/10.1053/j.gastro.2008.05.046.

203. Sun RF, Zhao CY, Chen S, Yu W, Zhou MM, Gao CR. Androgen receptor stimulates hexokinase 2 and induces glycolysis by PKA/CREB signaling in hepatocellular carcinoma. Dig Dis Sci. 2020. https://doi.org/10.1007/s10620020-06229-y.

204. Groupe d'Etude et de Traitement du Carcinome H. Randomized trial of leuprorelin and flutamide in male patients with hepatocellular carcinoma treated with tamoxifen. Hepatology. 2004;40:1361-9. https://doi.org/10. 1002/hep.20474

205. Manesis EK, Giannoulis G, Zoumboulis P, Vafiadou I, Hadziyannis SJ. Treatment of hepatocellular carcinoma with combined suppression and inhibition of sex hormones: a randomized, controlled trial. Hepatology. 1995;21:1535-42.

206. Xiao Y, Sun Y, Liu G, Zhao J, Gao Y, Yeh S, Gong L, Chang C. Androgen receptor (AR)/miR-520f-3p/SOX9 signaling is involved in altering hepatocellular carcinoma (HCC) cell sensitivity to the Sorafenib therapy under hypoxia via increasing cancer stem cells phenotype. Cancer Lett. 2019;444:175-87. https://doi.org/10.1016/j.canlet.2018.11.004.

207. Jiang X, Kanda T, Nakamoto S, Miyamura T, Wu S, Yokosuka O. Involvement of androgen receptor and glucose-regulated protein $78 \mathrm{kDa}$ in human hepatocarcinogenesis. Exp Cell Res. 2014;323:326-36. https://doi.org/10. 1016/j.yexcr.2014.02.017.

208. Kanda T, Takahashi K, Nakamura M, Nakamoto S, Wu S, Haga Y, Sasaki R, Jiang $X$, Yokosuka $O$. Androgen receptor could be a potential therapeutic target in patients with advanced hepatocellular carcinoma. Cancers (Basel). 2017;9. https://doi.org/10.3390/cancers9050043.

209. Safdie FM, Dorff T, Quinn D, Fontana L, Wei M, Lee C, Cohen P, Longo VD. Fasting and cancer treatment in humans: A case series report. Aging. 2009; 1:988-1007. https://doi.org/10.18632/aging.100114.

210. Goldstein I, Hager GL. Transcriptional and chromatin regulation during fasting - the genomic era. Trends Endocrinol Metab. 2015;26:699-710. https://doi.org/10.1016/j.tem.2015.09.005. 
211. Sukonina V, Ma H, Zhang W, Bartesaghi S, Subhash S, Heglind M, Foyn $H$, Betz MJ, Nilsson D, Lidell ME, Naumann J, Haufs-Brusberg S, Palmgren H, et al. FOXK1 and FOXK2 regulate aerobic glycolysis. Nature. 2019;566:27983. https://doi.org/10.1038/s41586-019-0900-5.

212. Bianchi G, Martella R, Ravera S, Marini C, Capitanio S, Orengo A, Emionite L, Lavarello C, Amaro A, Petretto A, Pfeffer U, Sambuceti G, Pistoia V, et al. Fasting induces anti-Warburg effect that increases respiration but reduces ATP-synthesis to promote apoptosis in colon cancer models. Oncotarget. 2015;6:11806-19. https://doi.org/10.18632/oncotarget.3688.

213. Grasl-Kraupp B, Bursch W, Ruttkay-Nedecky B, Wagner A, Lauer B, SchulteHermann R. Food restriction eliminates preneoplastic cells through apoptosis and antagonizes carcinogenesis in rat liver. Proc Natl Acad Sci U S A 1994; 91: 9995-9. doi: https://doi.org/10.1073/pnas.91.21.9995.

214. Ito J, Uchida H, Yokote T, Ohtake K, Kobayashi J. Fasting-induced intestinal apoptosis is mediated by inducible nitric oxide synthase and interferon\{gamma\} in rat. Am J Physiol Gastrointest Liver Physiol. 2010;298:G916-26. https://doi.org/10.1152/ajpgi.00429.2009.

215. Yoshida GJ. Emerging role of epithelial-mesenchymal transition in hepatic cancer. J Exp Clin Cancer Res. 2016;35:141. https://doi.org/10.1186/s13046016-0419-7.

216. Zhang Z, Li TE, Chen M, Xu D, Zhu Y, Hu BY, Lin ZF, Pan JJ, Wang X, Wu C, Zheng Y, Lu L, Jia HL, et al. MFN1-dependent alteration of mitochondrial dynamics drives hepatocellular carcinoma metastasis by glucose metabolic reprogramming. Br J Cancer. 2020;122:209-20. https://doi.org/10.1038/ s41416-019-0658-4.

217. Zhang Y, Zeng S, Ma J, Deng G, Qu Y, Guo C, Shen H. Nestin overexpression in hepatocellular carcinoma associates with epithelial-mesenchymal transition and chemoresistance. J Exp Clin Cancer Res. 2016;35:111. https:// doi.org/10.1186/s13046-016-0387-y.

218. Duran A, Hernandez ED, Reina-Campos M, Castilla EA, Subramaniam S, Raghunandan S, Roberts LR, Kisseleva T, Karin M, Diaz-Meco MT, Moscat J. p62/SQSTM1 by binding to vitamin D receptor inhibits hepatic stellate cell activity, fibrosis, and liver Cancer. Cancer Cell. 2016;30:595-609. https://doi. org/10.1016/j.ccell.2016.09.004.

219. Yoshida GJ, Azuma A, Miura Y, Orimo A. Activated fibroblast program orchestrates tumor initiation and progression; molecular mechanisms and the associated therapeutic strategies. Int J Mol Sci. 2019;20. https://doi.org/ 10.3390/ijms20092256.

\section{Publisher's Note}

Springer Nature remains neutral with regard to jurisdictional claims in published maps and institutional affiliations.

Ready to submit your research? Choose BMC and benefit from:

- fast, convenient online submission

- thorough peer review by experienced researchers in your field

- rapid publication on acceptance

- support for research data, including large and complex data types

- gold Open Access which fosters wider collaboration and increased citations

- maximum visibility for your research: over $100 \mathrm{M}$ website views per year

At $\mathrm{BMC}$, research is always in progress.

Learn more biomedcentral.com/submissions 